\title{
Deciphering the Contribution of Oriens-Lacunosum/ Moleculare (OLM) Cells to Intrinsic $\theta$ Rhythms Using Biophysical Local Field Potential (LFP) Models
}

\author{
(1)Alexandra P. Chatzikalymniou, ${ }^{1,2}$ and ${ }^{1}$ Frances K. Skinner ${ }^{1,3}$
}

DOI:http://dx.doi.org/10.1523/ENEURO.0146-18.2018

${ }^{1}$ Krembil Research Institute, University Health Network, Toronto, Ontario M5T 058, Canada, ${ }^{2}$ Department of Physiology, University of Toronto, Toronto, Ontario M5S 1A8, Canada, and ${ }^{3}$ Departments of Medicine (Neurology) and Physiology, University of Toronto, Toronto, Ontario M5S 1A8, Canada

\begin{abstract}
Oscillations in local field potentials (LFPs) are prevalent and contribute to brain function. An understanding of the cellular correlates and pathways affecting LFPs is needed, but many overlapping pathways in vivo make this difficult to achieve. A prevalent LFP rhythm in the hippocampus associated with memory processing and spatial navigation is the $\theta(3-12 \mathrm{~Hz})$ oscillation. $\theta$ rhythms emerge intrinsically in an in vitro whole hippocampus preparation and this reduced preparation makes it possible to assess the contribution of different cell types to LFP generation. We focus on oriens-lacunosum/moleculare (OLM) cells as a major class of interneurons in the hippocampus. OLM cells can influence pyramidal (PYR) cells through two distinct pathways: by direct inhibition of PYR cell distal dendrites, and by indirect disinhibition of PYR cell proximal dendrites. We use previous inhibitory network models and build biophysical LFP models using volume conductor theory. We examine the effect of OLM cells to ongoing intrinsic LFP $\theta$ rhythms by directly comparing our model LFP features with experiment. We find that OLM cell inputs regulate the robustness of LFP responses without affecting their average power and that this robust response depends on coactivation of distal inhibition and basal excitation. We use our models to estimate the spatial extent of the region generating LFP $\theta$ rhythms, leading us to predict that about 22,000 PYR cells participate in intrinsic $\theta$ generation. Besides obtaining an understanding of OLM cell contributions to intrinsic LFP $\theta$ rhythms, our work can help decipher cellular correlates of in vivo LFPs.
\end{abstract}

Key words: computational modeling; hippocampus; interneurons; local field potential; microcircuit; $\theta$ rhythms

\section{Significance Statement}

Oscillatory local field potentials (LFPs) are extracellularly recorded signals that are widely used to interpret information processing in the brain. $\theta(3-12 \mathrm{~Hz})$ LFP rhythms are correlated with memory processing, and inhibitory cell subtypes contribute in particular ways to $\theta$. While a precise biophysical modeling scheme linking cellular activity to LFP signals has been established, it is difficult to assess cellular contributions in vivo to LFPs because of spatiotemporally overlapping pathways that prevent the unambiguous separation of signals. Using an in vitro preparation that exhibits $\theta$ rhythms and where there is much less overlap, we build biophysical LFP models and uncover distinct inhibitory cellular contributions. This work brings us closer to obtaining cellular correlates of LFPs and brain function.

Received April 11, 2018; accepted July 10, 2018; First published August 22, 2018.

The authors declare no competing financial interests.
Author contributions: A.P.C. and F.K.S. designed research; A.P.C. performed research; A.P.C. analyzed data; A.P.C. and F.K.S. wrote the paper. 


\section{Introduction}

Oscillatory brain activities, as can be observed in EEGs and local field potentials (LFPs), are a ubiquitous feature of brain recordings (Buzsáki and Draguhn, 2004). Accumulating evidence indicates that they form part of the neural code by phasically organizing information in brain circuits (Wilson et al., 2015). The LFP is the low-frequency part $(<500 \mathrm{~Hz})$ of the extracellular signal. Due to its relative ease of recording, it is commonly used to measure neural activity. It originates from transmembrane currents passing through cellular membranes in the vicinity of a recording electrode tip (Einevoll et al., 2013), and its biophysical origin is understood in the framework of volume conductor theory (Nicholson and Freeman, 1975). Many sources contribute to the LFP (Buzsáki et al., 2012) and depend on the frequency range of the extracellular signal. Slower oscillations $(<50 \mathrm{~Hz})$ are generated by synaptic currents as opposed to higher frequency oscillations $(>90 \mathrm{~Hz})$ which are influenced by phase-modulated spiking activity (Schomburg et al., 2012). Determining the sources of LFP output is highly challenging in general, and contributions from remote and local activities can be non-intuitive (Herreras, 2016; Carmichael et al., 2017). In essence, it is far from clear how to interpret LFP recordings in light of contributions from many different cell types and pathways.

The hippocampus exhibits many LFP activities including $\theta$ and $\gamma$ rhythms (Buzsáki, 2006; Colgin, 2016). In particular, the prominent $\theta$ rhythm $(3-12 \mathrm{~Hz})$ is correlated with spatial navigation and episodic memory, rapid eye movement sleep and voluntary behaviors (Buzsáki, 2002). Recently, direct behavioral relevance of $\theta$ LFP rhythm phase-coding was demonstrated by delivering perturbations during specific phases of the $\theta$ rhythm to preferentially affect encoding or retrieval behaviors (Siegle and Wilson, 2014). This was done by optogenetically stimulating particular inhibitory cell types in the dorsal CA1 region of the hippocampus. Such exciting studies and several reviews (Klausberger and Somogyi, 2008; Kepecs and Fishell, 2014; Hattori et al., 2017) make it clear that the specifics of inhibitory cell types are fundamental to neural coding and brain function. In essence, if we are to understand the brain's code, i.e., behavior-related changes in

This work was supported by the Natural Sciences and Engineering Research Council of Canada (NSERC) Discovery Grants to F.K.S. A.P.C. was supported by a Unilever/Lipton OSOTF Graduate Fellowship, Margaret J. Santalo Scholarship (Department of Physiology, Toronto), and Ontario Graduate Scholarship (OGS).

Acknowledgements: We thank Katie Ferguson for her feedback and participation at early stages of this work, Benedicte Amilhon and Sylvain Williams for their helpful comments, and Alexandre Guet-McCreight for a careful reading of this work.

Correspondence should be addressed to Frances K. Skinner, Krembil Research Institute, Krembil Discovery Tower, Toronto Western Hospital, 60 Leonard Avenue 4KD510, Toronto, Ontario, M5T 0S8, Canada, E-mail: frances.skinner@gmail.com.

DOI:http://dx.doi.org/10.1523/ENEURO.0146-18.2018

Copyright (C) 2018 Chatzikalymniou and Skinner

This is an open-access article distributed under the terms of the Creative Commons Attribution 4.0 International license, which permits unrestricted use, distribution and reproduction in any medium provided that the original work is properly attributed. oscillatory activity, we need to understand how various cell-type populations contribute to LFP recordings.

A whole hippocampus in vitro preparation has been developed and spontaneously generates intrinsic $\theta$ (3-12 $\mathrm{Hz}$ ) rhythms (Goutagny et al., 2009). Given the combination of its reduced nature and robust rhythms, this preparation presents an opportunity to understand cellular contributions to LFP $\theta$ rhythms as we can remove several complicating factors by not needing to consider various pathways that exist in in vivo scenarios. Ambiguities are greatly reduced and our ability to understand cellular contributions to LFP recordings is greatly enhanced. Oriens-lacunosum/moleculare (OLM) cells are a major class of GABAergic interneurons (Maccaferri, 2005). They play an important role in gating information flow in the hippocampus by facilitating intrahippocampal transmission from CA3 while reducing the influence of entorhinal cortical inputs (Leão et al., 2012). Since OLM cells project to the distal dendrites of pyramidal (PYR) cells they would be expected to generate large LFP deflections due to larger dipole moments (Pettersen et al., 2012). However, these expectations may need to be modified since in addition to inhibiting distal layers they can have an effect on inner and middle layers, since they inhibit interneurons that target PYR cells at those layers (Leão et al., 2012).

In this article, we use computational modeling to determine the contribution of OLM cells to ongoing intrinsic LFP $\theta$ rhythms considering their interactions with local targets using the in vitro whole hippocampus preparation context. We take advantage of a previous modeling framework of inhibitory networks (Ferguson et al., 2015) and generate biophysical LFP computational models, and investigate the factors that influence $\theta$ LFP characteristics. By directly comparing our LFP models with experiment, we are able to constrain the required connectivity profile between OLM cells and other inhibitory cells types, as well as to show that OLM cells control the robustness, but not the power, of intrinsic LFP $\theta$ rhythms. We are also able to assess the spatial reach of the extracellular signal and so estimate the number of cells that contribute to the LFP signal. In general, we show how the many complex interactions lead to emergent LFP output that are nonintuitive and would not be possible to understand without biophysical LFP modeling in an experimentally constrained microcircuit context. As such, our work shows a way forward to obtain an understanding of cellular contributions to brain rhythms.

\section{Materials and Methods}

\section{Network model details}

This work builds on previously developed models described in Ferguson et al. (2015). Here, we provide a summary of specifics that are salient to the present study.

\section{Inhibitory cell types and numbers, PYR cell model}

The inhibitory network model consists of 850 cells and represents a volume of $1 \mathrm{~mm}^{3}$ as shown to be appropriate to obtain spontaneous $\theta$ rhythms in the in vitro whole hippocampus preparation (Ferguson et al., 2013, 2015; Goutagny et al., 2009). Four different types of inhibitory cells are included: basket/axo-axonic cells (BC/AACs), 
bistratified cells (BiCs), and OLM cells. BC/AACs comprise a 380-cell population and target somatic, perisomatic, and axo-axonic regions of PYR cells. The BiCs comprise a 120-cell population and target middle, apical and basal regions of PYR cells, and the OLM cells comprise a 350-cell population and target the distal, apical dendrites of PYR cells. As in Ferguson et al. (2015), the structure of the PYR cell model was based on the one used in Migliore and Migliore (2012) as implemented in the NEURON simulator (Carnevale and Hines, 2006; see ModelDB accession number 144541). The PYR cell model was used as a passive integrator of inputs from cell firings at the various layers of the hippocampus, and all active, voltage-gated channel conductances were set to zero. This overall network model is schematized in Figure $1 A$. With the exception of basal excitatory input, it is the same as used in Ferguson et al. (2015).

\section{Inhibitory cell models and drives}

The inhibitory cell models are single compartment, have an Izhikevich mathematical structure (Izhikevich, 2003) and were constructed by fitting to experimental data from whole-cell patch clamp recordings in the whole hippocampus preparation (Ferguson et al., 2015). All of the cell model parameter values are given in Ferguson et al. (2015). Parvalbumin-expressing (PV) cell types are BC/ AACs and BiCs, and somatostatin-expressing (SOM) cell types are OLM cells. Each cell model is driven by excitatory postsynaptic currents (EPSCs) taken directly from experiment (Huh et al., 2016) during ongoing spontaneous $\theta$ rhythms for PV or SOM cells. The EPSCs were designed to ensure that the inhibitory cells receive frequencymatched current inputs and at the same time have amplitudes and peak alignments that were consistent with $\theta$ oscillations in experiment (Ferguson et al., 2015; see EP$S_{P V}$ and $E_{P S C} C_{O L M}$ examples in Fig. 1A). Importantly, the experimental variability in amplitude and timing of EPSCs across cells was captured by varying the gain (factor by which the EPSC was scaled to alter the amplitude) and timing of the EPSCs across cells with a normal distribution in accordance with the experimental recordings. Thus, each inhibitory cell model received a unique set of excitatory synaptic inputs reflecting the range of amplitudes and timing of those recorded experimentally.

\section{Inhibitory network connectivity and output}

$\mathrm{PV}$ cells (BC/AACs and BiCs) were randomly connected with probabilities and synaptic conductance values based on experimental estimates from the literature and previous modeling work (Ferguson et al., 2013). Connections between BiCs and OLM cells are known to exist (Leão et al., 2012) and a range of values from the literature was previously estimated, with the connection probability from BiCs to OLM cells taken as 0.64 times the connection probability from OLM cells to BiCs (Ferguson et al., 2015). Although OLM-BiC connections exist, their synaptic conductance values are unclear but can be roughly estimated from the literature. In previous work, the balance of parameter values important for $\theta$ rhythms was specifically examined by exploring a wide range of values that encompassed determined estimates (Ferguson et al., 2015).
Inhibitory synapses were modeled using a first order kinetic process with appropriate rise and decay time constants. The spiking output of the inhibitory network models briefly described here were computed for the range of synaptic conductance strengths and connection probabilities given in Table 1. For the work in this paper we used output from these inhibitory networks. Specifically, these simulations were done for $5 \mathrm{~s}$; the connection probability from OLM cells to BiCs $\left(c_{s b}\right)$ varied from 0.01 to 0.33 with a step size of 0.02 producing 16 sets of connection probabilities; synaptic conductance values ranged from 0 to $6 \mathrm{nS}$ for OLM cells to BiCs $\left(g_{s b}\right)$ and for BiCs to OLM cells $\left(g_{b s}\right)$. By changing $g_{s b}$ and $g_{b s}$ with a step size resolution of $0.25 \mathrm{nS}, 625$ raster plots were produced. So the total number of raster plots in our study here as computed in Ferguson et al. $(2015)$ is $(625 \times 16)$ 10,000 , and they are all available on Open Science Framework (osf.io/vw3jh).

\section{Synaptic weights and distribution onto PYR cell}

Inhibitory inputs to the PYR cell model were distributed in the same way as done in Ferguson et al. (2015). That is, we distinguished between synapses at the distal layer (stratum lacunosum-moleculare), medial and basal layers (stratum radiatum and oriens), and the perisomatic/somatic layer [stratum pyramidale (SP)]. Distal synapses were defined as those that are $>475 \mu \mathrm{m}$ from the soma; apical and basal synapses were defined as those that are $>50-375 \mu \mathrm{m}$ from the soma; perisomatic/somatic synapses were defined as those that are $<30 \mu \mathrm{m}$ from the soma. We created three lists of components (where each component points to a specific segment of a section in the PYR cell model), for the possible distal, proximal apical/basal, and perisomatic/somatic synaptic targets. For each individual, presynaptic inhibitory cell model, we randomly chose a synaptic location on the passive CA1 PYR cell model from the respective list (distal dendrites for OLM cell models, apical/basal dendrites for BiC models, and perisomatic/somatic locations for BC/AACs). Then the spike times from the individual, inhibitory cell models filled a vector, and an artificial spiking cell was defined to generate spike events at the times stored in that vector at the specific location at which that cell created a synaptic target. We used the Exp2Syn function in NEURON to define the synaptic kinetic scheme of the synapse. This function defines a synapse as a synaptic event with exponential rise and decay, that is triggered by presynaptic spikes, and has a specific weight that determines its synaptic strength, and an inhibitory reversal potential of $-85 \mathrm{mV}$, as measured in the whole hippocampus preparation. Synaptic weight values onto the PYR cell from the different cell populations were estimated using somatic inhibitory postsynaptic current (IPSC) values for OLM cells onto PYR cells (Maccaferri et al., 2000). As these synaptic weights were not clearly known, we used different synaptic weight profiles in the explorations as was been done previously (Ferguson et al., 2015). The main profile used was graded such that the different cell types led to similar somatic IPSC amplitudes, considering that $0.00067 \mu \mathrm{S}$ can be estimated from the OLM cells IPSCs (Table 1). Several other synaptic weight profiles 
A
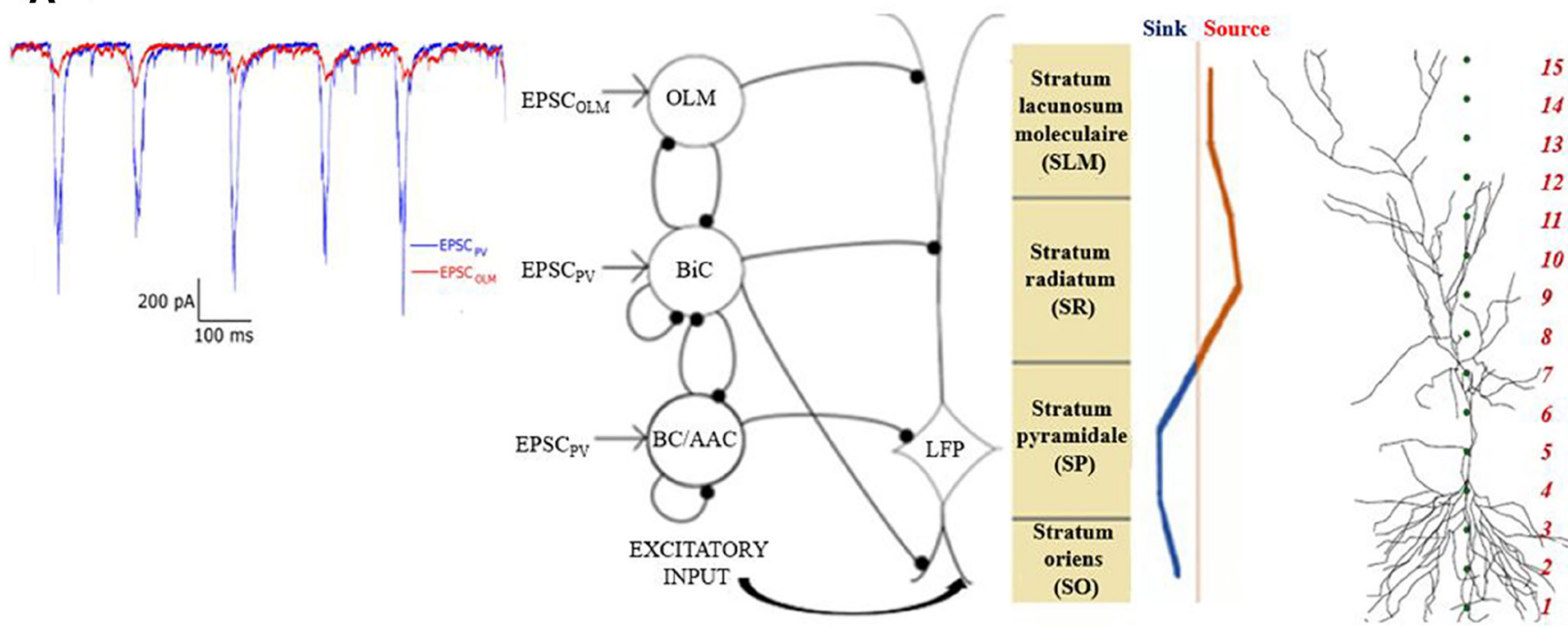

B

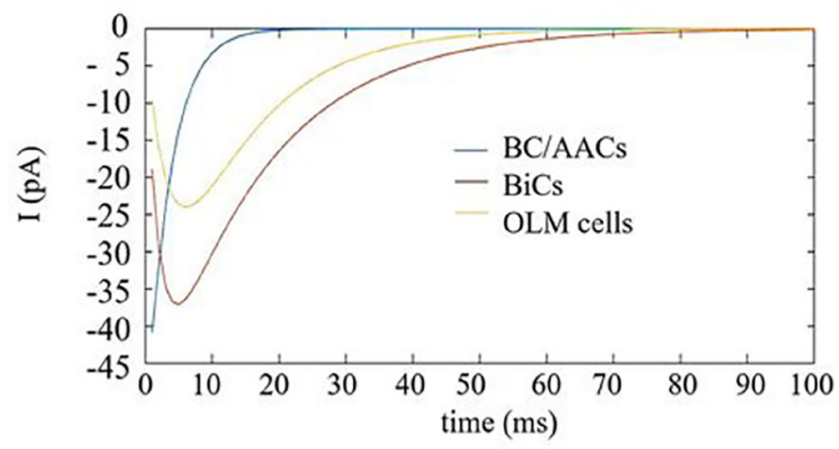

time (ms)

Simulation

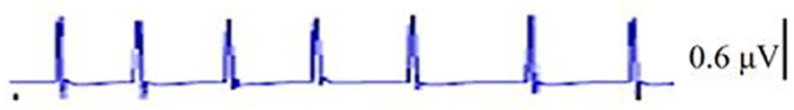

Experiment
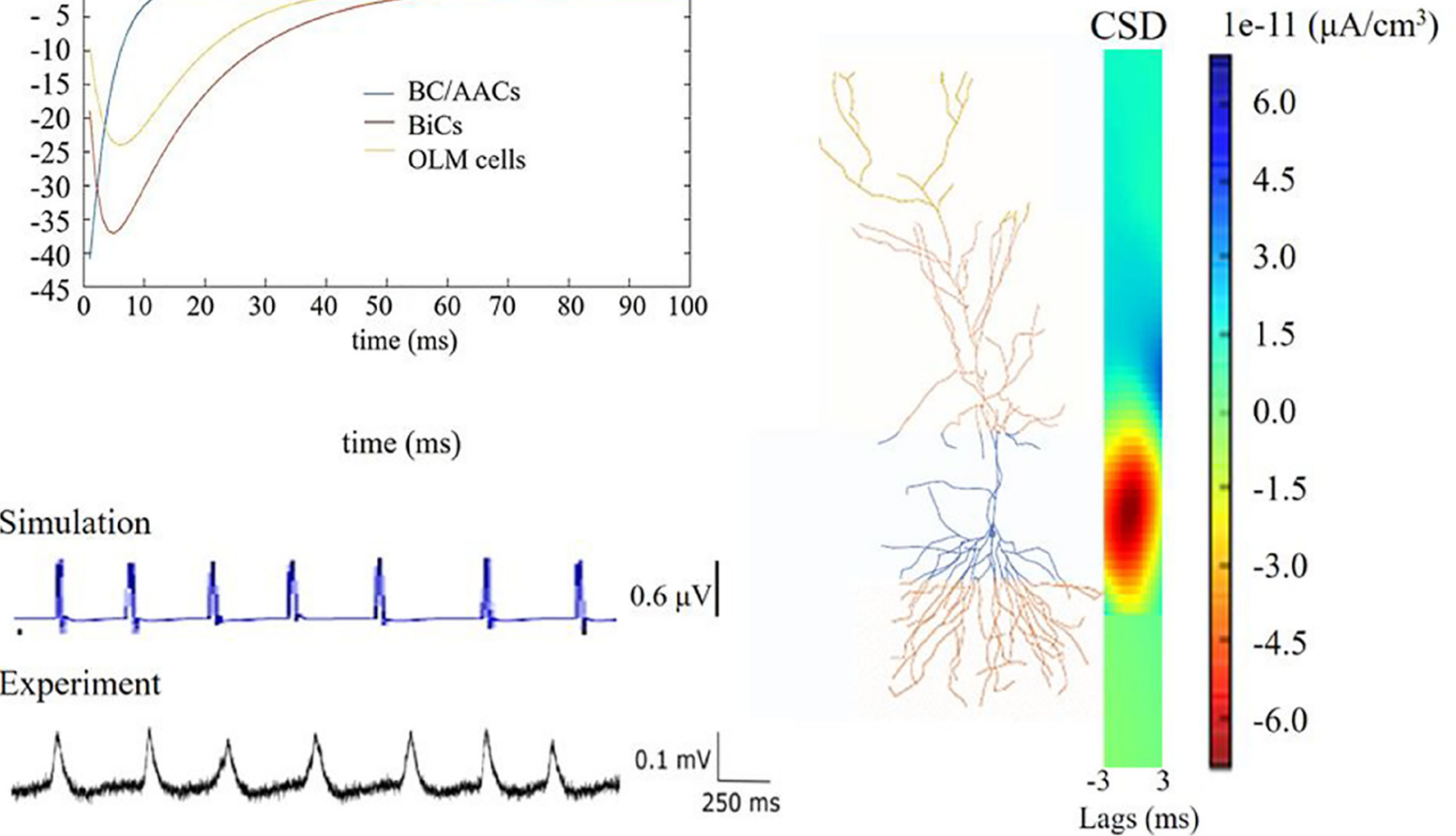

Figure 1. Model setup and experimental essence. A, A schematic of the network model used by Ferguson et al. (2015) is shown in the middle. The network model contains single compartment representations for OLM cells, BiCs, and BC/AACs. Inhibitory synapses are represented by filled black circles. Each inhibitory cell receives EPSCs that is taken from experimental intracellular recordings as shown on the far left (adapted from Ferguson et al., 2015). Each inhibitory cell synapses onto a PYR cell model as schematized. There are 350 OLM cells, $120 \mathrm{BiCs}$, and 380 BC/AACs. Basal excitatory input is also included. An illustration of the polarity changes (source/sink) seen in the different labeled layers from LFP experimental recordings is shown on the right, and the detailed PYR cell morphology that is used along with the 15 equidistant electrode locations in the different layers is shown as red numbers on the far right. $\boldsymbol{B}$, IPSCs from the different cell types (colored as indicated) are shown on the left to show their different kinetics. Parameter values are given in Table 1, and the same coloring is used on the detailed PYR cell morphology to indicate the synaptic location regions for the different cell types. An example simulation of a computed LFP from the SR layer (using parameter values of $g_{s b}=6$ and $g_{b s}=1.25 \mathrm{nS}, c_{s b}=0.21$ ) is shown below, and the computed CSD is shown on the right (averaged over time). On the bottom is an example of an experimental LFP recording from the SR layer (adapted from Ferguson et al., 2015). 
Table 1. Connectivity parameter values

\begin{tabular}{|c|c|c|c|c|}
\hline $\begin{array}{l}\text { Cell type } X \text { to cell } \\
\text { type } Y(X-Y)\end{array}$ & $\begin{array}{l}\text { Connection } \\
\text { probability }\end{array}$ & $\begin{array}{l}\text { Maximal synaptic Conduc.(nS) } \\
\text { or synaptic weight }(\mu \mathrm{S}) \\
\text { to PYR cell }\end{array}$ & $\begin{array}{l}\text { Synaptic rise } \\
\text { time (ms) }\end{array}$ & $\begin{array}{l}\text { Synaptic decay } \\
\text { time (ms) }\end{array}$ \\
\hline$\overline{B C / A A C ~-~ B C / A A C ~}$ & 0.12 & 3 & 0.27 & 1.7 \\
\hline $\begin{array}{l}\text { BC/AAC - BiC } \\
\text { BC/AAC - OLM cell } \\
\text { BC/AAC - PYR cell }\end{array}$ & $\begin{array}{l}0.12 \\
0 \\
1\end{array}$ & $\begin{array}{l}3 \\
\text { N/A } \\
0.00038\end{array}$ & $\begin{array}{l}0.27 \\
\text { N/A } \\
0.3\end{array}$ & $\begin{array}{l}1.7 \\
\mathrm{~N} / \mathrm{A} \\
3.5\end{array}$ \\
\hline$\overline{\mathrm{BiC}}-\mathrm{BC} / \mathrm{AAC}$ & 0.12 & 3 & 0.27 & 1.7 \\
\hline $\begin{array}{l}\mathrm{BiC}-\mathrm{BiC} \\
\mathrm{BiC}-\mathrm{OLM} \text { cell } \\
\mathrm{BiC}-\mathrm{PYR} \text { cell }\end{array}$ & $\begin{array}{l}0.12 \\
0-0.224 \\
1\end{array}$ & $\begin{array}{l}3 \\
0-6 \\
0.00044\end{array}$ & $\begin{array}{l}0.27 \\
2 \\
2\end{array}$ & $\begin{array}{l}1.7 \\
16.1 \\
16.1\end{array}$ \\
\hline OLM cell - BC/AAC & 0 & $\mathrm{~N} / \mathrm{A}$ & $\mathrm{N} / \mathrm{A}$ & $\mathrm{N} / \mathrm{A}$ \\
\hline $\begin{array}{l}\text { OLM cell - BiC } \\
\text { OLM cell - OLM cell } \\
\text { OLM cell - PYR cell }\end{array}$ & $\begin{array}{l}0-0.33 \\
0 \\
1\end{array}$ & $\begin{array}{l}0-6 \\
\text { N/A } \\
0.00067\end{array}$ & $\begin{array}{l}2 \\
\mathrm{~N} / \mathrm{A} \\
3.5\end{array}$ & $\begin{array}{l}16.1 \\
\text { N/A } \\
11.8\end{array}$ \\
\hline $\begin{array}{l}\text { Excitatory input } \\
\text { to PYR cell } \\
\text { (197 contacts to basal tree) }\end{array}$ & 1 & 0.00044 & 0.5 & 3 \\
\hline
\end{tabular}

$\mathrm{N} / \mathrm{A}=$ not applicable

were examined. Finally, we note that an ad hoc representation for LFPs was previously used (Ferguson et al., 2015) as given by an inverted summation of all integrated inputs as measured at the PYR cell soma. That is, the postsynaptic potentials on the PYR cell were due to the various inhibitory cell firings that comprised the presynaptic spike populations.

\section{Additional network model details for this study}

For the study here, inhibitory inputs were distributed in the same way as in Ferguson et al. (2015). In Ferguson et al. (2015), the literature was used to estimate synaptic conductances between OLM cells and BiCs as 3-4 nS, and Bezaire et al. (2016) used 10 synapses/connection as estimates in their detailed data-driven computational models. This implies that a single synapse would be 0.3-0.4 nS, representing an approximate minimum connection weight.

As we made direct comparisons with $\theta$ LFP experimental recordings here, it was important to include excitatory input to the PYR cell model. Thus, we also included excitation due to CA1 recurrent collaterals which synapse on basal dendrites (Takács et al., 2012). In Ferguson et al. (2015), excitatory feedback was not included in a direct fashion as the focus was on ongoing $\theta$ rhythms and OLM-BiC interactions, and not on $\theta$ generation mechanisms explicitly. Thus, model excitatory cell populations were not specifically modeled. This means that we did not have explicit spike rasters for excitatory populations as we did for the inhibitory cell populations. Rather than generate an arbitrary set of spike times to simulate excitatory inputs, we used spike times from a BiC raster $\left(g_{s b}=\right.$ $3.75, g_{b s}=1.75 \mathrm{nS}, c_{s b}=0.21$ ), in which the neuron order was randomized, and with comparable synaptic weights. Using these random spike trains we generated spike vectors exactly as in the case of interneurons and randomly distributed them on basal dendrites using 197 synapses based on number estimates from Bezaire and Soltesz
(2013) and Bezaire et al. (2016). In this way, we did not have a spatiotemporal dominance of inhibitory or excitatory input in basal dendrites. We used an excitatory reversal potential of $-15 \mathrm{mV}$ as measured in the whole hippocampus preparation, and synaptic time constants in line with modeling work (Ferguson et al., 2017). In essence, we simulated EPSCs using random spike trains of $\theta$ frequency instead of explicitly modeling PYR cell spiking activity. We note that with these choices, somatically recorded currents in our PYR cell models were similar to what is observed in experiments (Huh et al., 2016). All parameter values are summarized in Table 1.

We note that the inhibitory cell spike rasters computed in Ferguson et al. (2015) used random connectivities between the different inhibitory cell populations. Consider that a given set of parameters $\left(c_{s b}, g_{s b}, g_{b s}\right)$ defines a connectivity map. Each cell within a given population is randomly assigned a synaptic location within the boundaries of the dendritic tree on which it projects. Based on a given connectivity map the spiking activity of the various cell populations will differ. Therefore, the characteristics of the produced biophysical LFP will depend on the spike distribution of a given population defined by the connectivity map and also the number and location of synapses on the dendritic tree. To ensure that our LFP output was not dependent on the specific synaptic location that every cell was assigned to, we generalized our observations by performing many trials for a given connectivity map, assigning randomly different location to the cells of each population to ensure that the LFP output was not dependent on that aspect.

\section{Biophysical computation of LFP}

Extracellular potentials are generated by transmembrane currents (Nunez and Srinivasan, 2006). In the commonly used volume conductor theory, also used here, the extracellular medium was modeled as a smooth threedimensional continuum with transmembrane currents 
representing volume current sources. The fundamental formula (Pettersen et al., 2012) relating neural activity in an infinite volume conductor to the generation of the LFP $\phi(r, t)$, at a position $r$ is given by:

$$
\phi(r, t)=\frac{1}{4 \pi \sigma} \sum_{k=1}^{n} \frac{I_{k}(t)}{\left|r-r_{k}\right|}
$$

Here, $I_{\mathrm{k}}$ denotes the transmembrane current (including the capacitive current) in a neural compartment $k$ positioned at $r_{k}$, and the extracellular conductivity, here assumed real (ohmic), isotropic (same in all directions) and homogeneous (same at all positions), is denoted by $\sigma$. In the hippocampus the mean extracellular conductivity $\sigma$ is equal to $0.3 \mathrm{~S} \mathrm{~m}^{-1}$ (López-Aguado et al., 2001), which is the value that we used for our simulations. A key feature of Equation 1 is that it is linear, i.e., the contributions to the LFP from the various compartments in a neuron sum up. Likewise, the contributions from all the neurons in a population would add up linearly. The transmembrane currents $I_{k}$ setting up the extracellular potentials according to Equation 1 were calculated by means of standard multicompartment modeling techniques, here by use of the simulation tool NEURON Carnevale and Hines (2006). The current source densities (CSDs) in Figure $1 B$ were computed using the 1D KCSD inverse method proposed in Potworowski et al. (2012). The CSDs were computed from the LFP measured by electrodes that are arranged along a straight line, in this case along the cellular axis of the PYR cell.

The same PYR cell multi-compartment model as described above was used to compute the extracellular biophysical LFP, and we used the set of 10,000 5-s raster plots (of inhibitory spikes) as described above for our presynaptic populations with the addition of basal excitation. That is, we generated extracellular potential traces (5 $s$ each) due to the various inhibitory cell firings. We used a single multi-compartment PYR cell to compute the biophysical LFP. While an experimental LFP is generated by many cells, we still referred to our extracellular output as an "LFP" for consistency with the computational literature, where the LFP term has been used for an extracellular field from single or multiple cells.

\section{Simulation details}

The computational simulations and analyses were performed using the LFPy python package RRID:SCR_014805 (Lindén et al., 2014), NEURON RRID:SCR_005393 (Carnevale and Hines, 2006), and MATLAB RRID:SCR_001622 (MATLAB 8.0 and Statistics Toolbox 8.1). The large scale network simulations were conducted using high-performance computing at SciNet (Loken et al., 2010). The code/software described in the paper is freely available online at https://github.com/FKSkinnerLab/LFP_microcircuit.

\section{Results}

\section{Intrinsic $\theta$ rhythms in the hippocampus}

It has long been known that input from the medial septum is an important contributor to in vivo LFP $\theta$ rhythms (Buzsáki, 2002). However, recent work by Goutagny et al. (2009) showed that $\theta$ rhythms can emerge in the CA1 region of an intact in vitro hippocampus preparation. These intrinsic $\theta$ rhythms appeared spontaneously without any pharmacological manipulations or artificial stimulation paradigms, and persisted even after the neighboring CA3 subfield was removed. It is thus clear that intrinsic $\theta$ frequency rhythms can be produced by local interactions between interneurons and PYR cells in the hippocampus. That is, the CA1 region of the hippocampus contains sufficient circuitry to be able to generate $\theta$ oscillations. An example of this intrinsic LFP rhythm is shown in Figure $1 B$. Considering this preparation, a one cubic millimeter estimate of the tissue size (i.e., network circuitry) needed for intrinsic $\theta$ rhythm to occur was estimated (Ferguson et al., 2013). While it is clear that these intrinsic $\theta$ rhythms do not fully encompass in vivo $\theta$ rhythms, they undoubtedly exist without any special manipulations, and so are arguably part of the underlying biological machinery generating $\theta$ rhythms in the hippocampus. More importantly, to have a chance to understand the many different cellular contributions to LFP recordings, this preparation can be used to decipher the many interacting components.

To examine the role of specific hippocampal interneurons in these intrinsic $\theta$ rhythms, Amilhon et al. (2015) optogenetically activated and silenced PV or SOM interneurons. PV cell types exhibiting fast firing characteristics include BCs, AACs, and BiCs (Baude et al., 2007). OLM cells are SOM-positive, but it is not the case that SOM interneurons are necessarily OLM cells. However, reconstructions of SOM cells in these studies with intrinsic $\theta$ were done, confirming that they are likely OLM cells (Huh et al., 2016). Amilhon et al. (2015) found that optogenetic manipulation of SOM cells modestly influenced the intrinsic $\theta$ rhythms. In contrast, activation or silencing of PV cells strongly affected $\theta$. These results thus demonstrated an important role for PV cells but not SOM cells for the emergence and presence of intrinsic hippocampal $\theta$, as given by the observed LFP recordings exhibiting $\theta$ rhythms.

LFP recordings in this preparation had a particular sink and source distribution in the different layers (Goutagny et al., 2009). It is given by a single dipole characterized by positive deflections in stratum lacunosum/moleculare (SLM) and stratum radiatum (SR) and negative deflections in SP and stratum oriens (SO). The dipole is illustrated in Figure $1 A$. This LFP laminar polarity profile was consistent across preparations. We note that since $\theta$ rhythms persisted even when the CA3 region was removed, excitatory collaterals from CA3 did not seem to be a necessity for the emergence of the rhythm and the sink/source density profile. Thus, in our LFP model in this work, we assumed that excitatory input to CA1 PYR cells was restricted to the basal dendrites due to CA1 PYR cell collaterals (Goutagny et al., 2009).

\section{Using a previous network model framework as a basis}

To try to understand how the complex interactions between different inhibitory cell types contributed to $\theta$ 
LFP rhythms, a computational network framework representing CA1 microcircuitry was previously developed (Ferguson et al., 2015). Given the ambiguous role of OLM cells in $\theta$ rhythms and the newly discovered connections between OLM cells and BiCs (Leão et al., 2012), these network models were developed to explore how OLM-BiC interactions influenced the characteristics of $\theta$ rhythms. We took advantage of previously developed PV fast-firing cell models (Ferguson et al., 2013) and OLM cell models (Ferguson et al., 2015) based on recordings from the whole hippocampus preparation. Because of distal contacts of OLM cells with PYR cells, a multi-compartment PYR cell model was previously used to be able to incorporate this aspect in exploring the various interactions. The network model framework is shown in Figure $1 A$, and a summary of the network model is provided in Materials and Methods. We note that the network model was designed to explore cellular interactions and contributions to the ongoing intrinsic $\theta$ rhythms, and not to the generation of the $\theta$ rhythms explicitly. All inhibitory neurons were driven by $\theta$ frequency inputs based on experimental recordings from the whole hippocampus preparation.

As schematized in Figure $1 A$, the inhibitory cell populations encompassed BC/AACs, BiCs and OLM cells that were driven by experimentally derived EPSCs. These EPSCs were from the ongoing rhythm and were of $\theta$ frequency (Fig. 1A). Spiking output from the inhibitory cell populations led to IPSCs on the PYR cell. They were distributed on the PYR cell according to where the particular cell population targeted. Thus, BC/AACs to somatic regions, BiCs to middle apical and basal regions and OLM cells to distal apical regions. IPSCs generated by the different cell types are shown in Figure $1 B$ (for details, see Materials and Methods). In previous work, the spatial integration of the inhibitory postsynaptic potentials at the soma of a passive PYR cell model was used as a simplistic LFP representation (Ferguson et al., 2015). This representation was in fact indicative of the intracellular somatic potential rather than the extracellular one, but it did allow the distal OLM cell inputs relative to more proximal PV cell inputs to be taken into consideration. Using this computational model framework, multiple simulations were performed and it was shown that there were parameter balances that resulted in high or low $\theta$ power, and where OLM cells did or did not affect the $\theta$ power (Ferguson et al., 2015). That is, OLM cells could play a small or large role in the resulting $\theta$ power depending on whether compensatory effects with BiCs occurred as a result of the size and amount of synaptic interactions between these cell types. Thus, interactions between OLM cells and BiCs in the CA1 microcircuitry seemed to be an important aspect for the presence of intrinsic LFP $\theta$ rhythms. However, since an ad hoc LFP representation was used, it was not possible to do any direct comparisons with experimentally recorded LFPs to decipher their output. That is, the possibility to parse out the contribution of the different cell types or identify particular interactions was limited. Thus, while it was possible to show that interactions between OLM cells and BiCs could play an essential role in the resulting $\theta$ power, it was not possible to predict any particular parameter balances or to extract possible explanations.

In the work here, we built on this model framework and developed biophysical LFP models. We used the inhibitory spiking output generated in Ferguson et al. (2015) as a basis for generating biophysical LFPs, and we used the same PYR cell model. However, unlike the previous work, we used the framework of volume conductor theory (see Materials and Methods) and generated actual extracellular potential output as a result of the overall activity of the inhibitory cell firings across the various layers of CA1 hippocampus. In addition, we included excitatory input onto the basal dendrites to represent recurrent CA1 inputs (see schematic in Fig. 1A; for details, see Materials and Methods) and directly compared with characteristics of experimental LFP recordings. It is important to note that the structure of our model here did not focus on deciphering the generation of $\theta$ rhythms directly. Rather, there was the point neuron network model with the inhibitory cells receiving $\theta$ frequency EPSC inputs and the multi-compartment PYR cell model generating biophysical LFP output based on the synaptic inputs it was receiving. In this way, we were able to do extensive parameter explorations and to focus on comparing model and experimental LFPs to gain insight.

\section{Overall characteristics of biophysical LFP models}

From the previous modeling study of Ferguson et al. (2015), several sets of inhibitory spiking output with particular connection probabilities and particular synaptic conductances between OLM cells and BiCs were available. The connection probability from OLM cells to BiCs $\left(c_{s b}\right)$ varied from $0.01-0.33$ with a step size of 0.02 producing 16 sets of connection probabilities; synaptic conductance values ranged from $0-6 \mathrm{nS}$ for OLM cells to BiCs $\left(g_{s b}\right)$ and for BiCs to OLM cells $\left(g_{b s}\right)$ with a step size of $0.25 \mathrm{nS}$. Thus, for a given connection probability, there were 625 sets of spiking outputs from inhibitory cells, where each set represented a 850-cell inhibitory network with particular synaptic conductances. We considered a set to be a connectivity map representing the inhibitory cell populations.

For each connectivity map, we generated a biophysical, extracellular LFP. A virtual electrode probe was placed along the vertical axis of the PYR cell model to record its LFP output in a layer dependent manner. This PYR cell model was the "processor" of the LFP signal as it integrated postsynaptic inputs from different presynaptic populations. We computed LFPs at 15 equidistant sites along a linear axis (Fig. 1A). The PYR cell output corresponded to readouts of the postsynaptic activity elicited by the afferent inhibitory cell populations that targeted the PYR cell in appropriate regions, referred to as the LFP "generator." We note that although there was a single connectivity map representing the randomly connected inhibitory cell population, we performed several trials when randomly targeting the PYR cell to ensure the robustness of our results (see Materials and Methods). To achieve effective electroneutrality, the extracellular sink needed to be balanced by an extracellular source, that is, 
an opposing ionic flux from the intracellular to the extracellular space, along the neuron; this flux was termed the "return current."

We developed some initial intuition regarding the generation of our biophysical LFPs by computing them without including basal excitation. That way, all of the inputs received by the PYR cell model were inhibitory. Figure $2 A, B$ illustrates the process and shows some examples. Let us first focus on Figure 2Ai. Next to each cell population in the network schematic are two examples of 1-s raster plots of spiking outputs (from the previously computed 5-s inhibitory network simulations in Ferguson et al., 2015) produced for particular parameter sets. These spikes gave rise to IPSCs on the PYR cell model and the computed extracellular LFP at the somatic layer is shown in Figure 2Aii. As shown, these particular parameter sets produced LFPs with positive or negative deflections. Let us next focus on Figure $2 \mathrm{Bi}$. One example of a 1-s raster plot is shown, and for this parameter set, the LFP had only a few positive deflections, as shown in Figure 2Bii. Assuming that one population burst in the raster plot leads to a single peak in the LFP, there would be $\sim 29$ peaks in the LFP for a 5-s simulation (i.e., $\sim 5.8-\mathrm{Hz}$ frequency), since our inhibitory cell raster plots have 28-29 population bursts. Note that the raster plots in Figure $2 \mathrm{Bi}$ were not very different from the examples shown in Figure $2 A i$. We computed LFPs at all layers as represented by the 15 virtual electrodes shown in Figure $1 A$ for the 625 sets of inhibitory spiking outputs across $g_{s b}$ and $g_{b s}$ values at a particular connection probability $c_{s b}$. The colored plot in Figure 2Aiii shows the polarity of the LFPs at the somatic layer, and the color plot in Figure 2Biii shows the number of LFP peaks in the somatic layer. In Figure $2 C$, normalized spike numbers for all interneuron populations are shown.

As a first approximation, given the network model framework and previous work, we can say the following about the LFPs: those governed mainly by synaptic inputs and not return currents were characterized by narrow wave form shapes as the synaptic inputs from any particular interneuron population enters the PYR cell in a synchronized fashion. This was due to the inhibitory cells in a given population being driven by rhythmic EPSCs that gave rise to coherently firing inhibitory cells in a given population (see example raster plots). We note that the EPSCs that were used in the simulations were not perfectly synchronized since the measured experimental variability was included in designing the EPSC inputs to use in the inhibitory network simulations (see Materials and Methods). On the other hand, return currents constituted a summation of less synchronized exiting currents that originally entered the cell at different locations. Therefore, LFP deflections governed by return currents were generally wider. Further, we would expect that the LFP recorded from different layers would first and foremost be influenced by the interneurons that project to that region. We also note that the width of the LFP deflection would not only be influenced by the nature of the current (synaptic inputs or return currents) but also by the synaptic time constants defining the shape of the IPSCs. IPSCs for the different cell populations are shown in Figure $1 B$, where it can be seen that the IPSCs produced by OLM cells and BiCs were wider relative to the IPSCs from BC/AACs. Thus, we expected that positive LFP deflections would be recorded in locations where OLM cells, BiCs, and BCs project, with wider LFPs for OLM cell projection locations, and that LFPs dominated by return currents would be recorded in locations where there were no direct inputs from interneurons. However, due to interactions between BiCs and OLM cells, this was not necessarily the case as return currents from distant interneuronal inputs could prevail in regions where other interneurons directly projected. In fact, interactions between OLM cells and BiCs can strongly modulate the relative balance between synaptic inputs and return currents, which in turn can strongly modulate the distribution of sinks and sources in the resulting LFP.

The two examples of LFP output at the somatic layer in Figure 2Aii show one with narrow positive deflections and the other with wider negative deflections. This thus indicated that the BC/AAC inputs that synapse at the somatic layer dominated for the positive deflection LFP example whereas $\mathrm{BiC}$ and OLM cell inputs that synapse more distally dominated for the negative wider deflection LFP example. The example in Figure 2Bii of LFP output at the somatic layer indicated that a loss of peaks can occur due to the superposition of synaptic inputs and return currents. Another "loss of peaks" example is shown in Figure 2Biv, and LFP output from multiple layers is shown in addition to the intracellular somatic output. For this example, the peak loss was also partially reflected in the intracellular somatic output. However, loss of peaks in the LFP output was not necessarily reflected in the somatic intracellular recording. Note that since the PYR cell was only receiving inhibitory input in these set of simulations, somatic intracellular potentials always had negative deflections. How the extracellular potential features changed as a function of the synaptic conductances between BiCs and OLM cells is summarized in the color plots of Figure 2Aiii for the polarity and Figure 2Biii for the number of peaks (somatic layer).

Let us consider Figure 2Aiii. We found that we can approximately distinguish four regions as $g_{s b}$ was increased. These regions are separated by dotted lines in Figure 2 Aiii and labeled $a$ to $d$. For small $g_{s b}$ values $(0-1$ $\mathrm{nS}$, region a) the amount of inhibition that the BiCs received from the OLM cells was minimized allowing the $\mathrm{BiCs}$ to be at the peak of their activity (Fig. 2C). Consequently, the inhibition that the OLM cells and BC/AACs received from the BiCs was maximized causing their activities to be minimized (Fig. 2C). As a result, the extracellular potential in the somatic region was governed by return currents leading to negative polarity LFPs in the somatic layer (i.e., mainly dark-colored in region a of Fig. 2 Aiii), primarily due to the $\mathrm{BiC}$ synaptic inputs on the "middle" region (SR layer) and "basal" region (SO layer) of the PYR cell. As we increased $g_{s b}$ (1-3.5 nS, region $\left.b\right)$, we encountered mainly positive polarity LFPs (i.e., lightcolored in region $b$ of Fig. 2Aiii). In region $b$, the inhibition onto the BiCs was increased and thus their activity was 
A

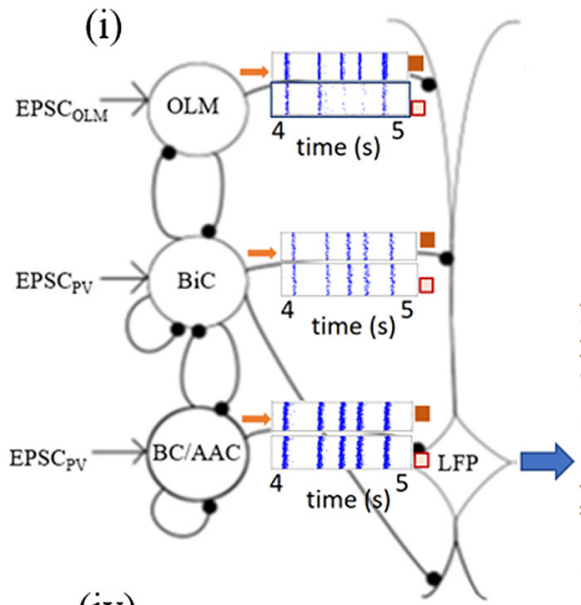

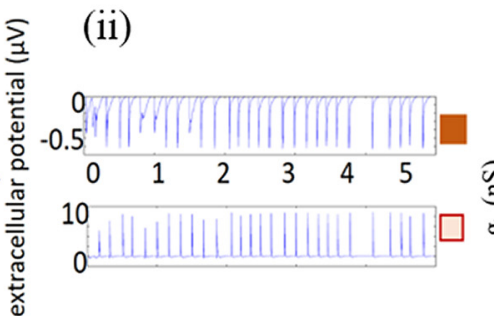

(iii)

Polarity

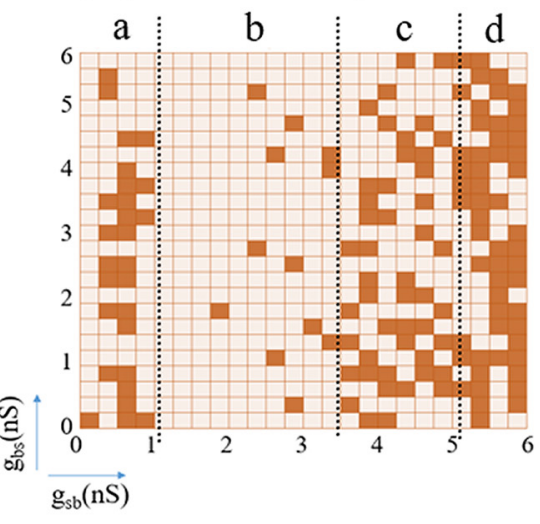

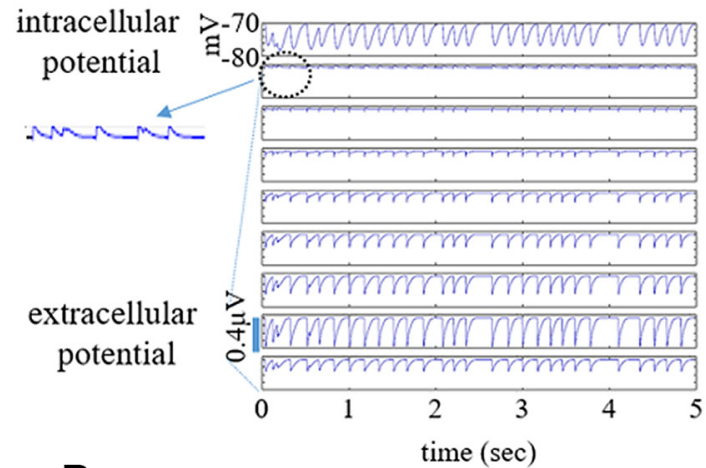
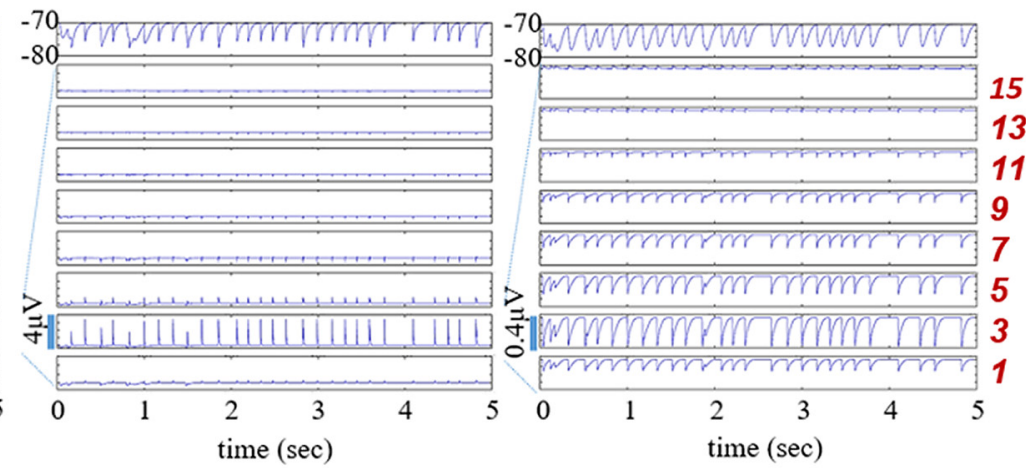

B (i)

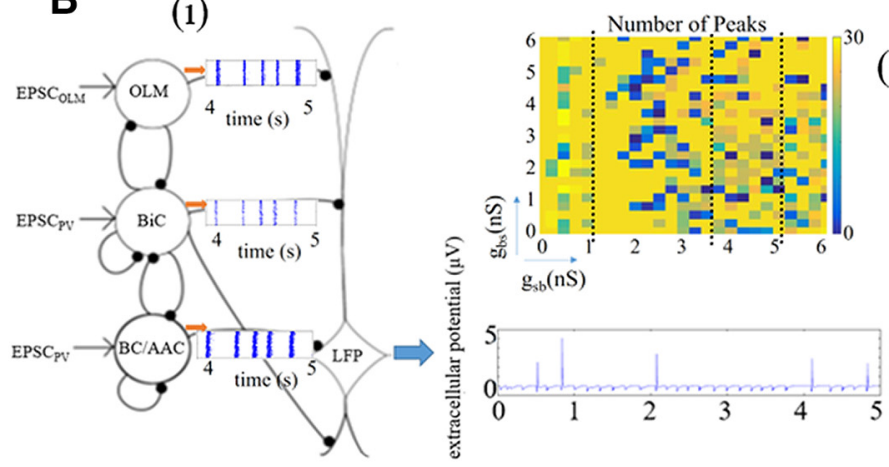

(iii)

(ii)

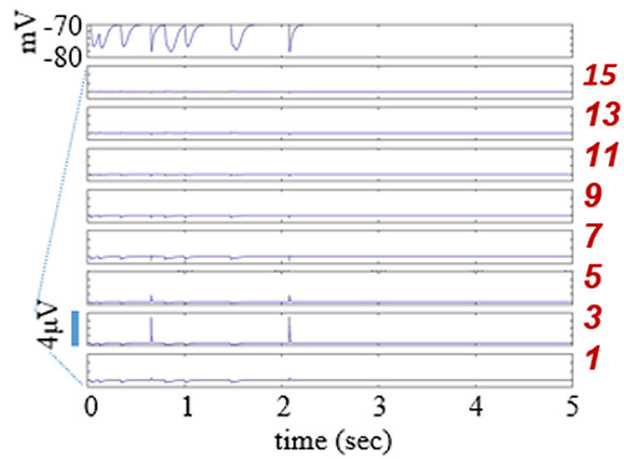

(iv)

C
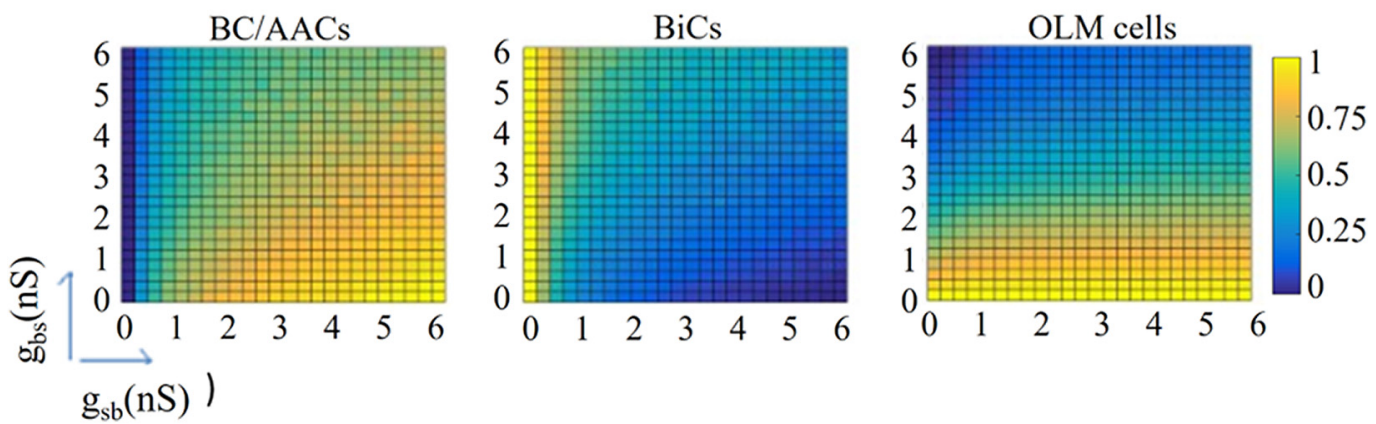

Figure 2. Biophysical LFP computation: features, examples, and interneuron activities. Ai, Schematic shows two raster plot examples for the given inhibitory cell population rasters. Aii, The resulting LFPs at the somatic layer, with positive and negative deflections is shown for the examples, labeled with dark- or light-colored squares. Parameter values are $g_{s b}=1.5, g_{b s}=5.5 \mathrm{nS}$ for positive and $g_{s b}=0.5, g_{b s}=0.75 \mathrm{nS}$ for negative deflections. Aiii, The color plot on the right shows the polarity at the somatic layer, SP, electrode 4. Dotted lines delineate four regions labeled as a, b, c, and d. Negative polarity: dark-colored squares, positive polarity: light-colored 


\section{continued}

squares. Aiv, LFP output for all layers are shown for three examples where the polarity is negative, positive and negative at electrode 3 (left to right). Parameter values are (left to right): $g_{s b}=0.5, g_{b s}=0.75 ; g_{s b}=1.5, g_{b s}=5.5 ; g_{s b}=5.75, g_{b s}=0.75 \mathrm{nS}$. Inset shows a blow up of LFP output at electrode 13 (SLM) to show positive deflections. Also shown is the intracellular somatic potential of the PYR cell. No basal excitation is present, $C_{s b}=0.21$. Bi, Schematic includes one raster plot example. Bii, The resulting LFP output at SP has five peaks. A maximum of 29 peaks is possible (see text). Parameter values are $g_{s b}=2, g_{b s}=0.75 \mathrm{nS}$. Biii, The color plot shows the number of peaks that appear in the 5-s LFP computation at SP, electrode 4 . Dotted lines delineate the same regions as in A. Biv, An example of LFP output for all layers as well as the intracellular somatic output which also shows a loss of peaks. Parameter values are $g_{s b}=2.25, g_{b s}=5.0 \mathrm{nS}$. No basal excitation is present, $c_{s b}=0.21$. C, Interneuron activity for each interneuron population, normalized such that the number of spikes for a given pair of synaptic conductances is divided by the maximal number considering all pairs of synaptic conductances. Maximal number (5-s trace): 16327 (BC/AACs), 6808 (OLM cells), 4 589 (BiCs).

decreased, as can be seen in Figure 2C, causing a decrease in the amount of the inhibitory current onto the PYR cell from BiCs. As a result, the magnitude of the return currents caused by the BiC synaptic inputs was decreased at the somatic layer. Simultaneously their ability to inhibit the BC/AACs was also decreased so that the BC/AACs became more active and their direct inhibition onto the PYR cell also increased. Since both BiCs and OLM cells activity was low in region $b$, while BC/AAC activity was increased, the somatic LFP was governed by BC/AAC inputs rendering the extracellular LFP positive. As we further increased $g_{s b}(3.5-5 \mathrm{nS}$, region $c)$ the silencing of the BiCs increased even further and their ability to silence the BC/AACs was further reduced. Simultaneously OLM cell activity increased. Thus, the somatic LFP was influenced by direct synaptic inputs from BC/AACs and also return currents from OLM cells (sparse darkcoloring region $c$ ). Interestingly, the majority of the loss of peaks in somatic LFP output occurred in regions $b$ and $c$ (see blue-green pixels in the Fig. 2Biii), where superposition of synaptic inputs and return currents was mostly occurring. That is, cancellations occurred even leading to abolishment of the entire rhythm sometimes. Finally, for $g_{s b}$ from 5.0-6 nS (region d), the BiCs were maximally inhibited and BC/AACs were at the peak of their activity. While we might have expected domination from the BC/ AAC synaptic inputs for these values, it turns out that return currents (negative polarity) dominated. This can be explained by the increased activity of OLM cells which were also at the peak of their activity producing strong return currents in the somatic region. In summary, lightcolored regions in Figure 2Aiii signify that BC/AACs dominated the extracellular somatic potential and darkcolored regions signify that other inhibitory cell types (BiCs or OLM cells, or both) contributed more strongly.

In Figure 2Aiv, we show three examples of LFP recordings at multiple layers as well as the somatic intracellular potential, for increasing values of $g_{s b}$ from left to right. To allow an appreciation of the changing magnitude of the signal, we used the same resolution on the ordinate axis for all LFP plots shown. On the left $\left(g_{s b}=0.5 \mathrm{nS}\right)$ we see that the signal was governed by return currents (negative polarity) in the entire SP (electrodes 3 and 5), in SO (electrode 1), and in SR (electrodes 7, 9, and 11). Synaptic events governed SLM (electrodes 13 and 15) where OLM cells directly project leading to positive polarity. In the middle $\left(g_{s b}=1.5 \mathrm{nS}\right)$, the LFP in SP and SO was governed by synaptic inputs (positive polarity), and in SR and
SLM by return currents (negative polarity). As expected, we found that the positive polarity LFP in SP here was narrower relative to the positive polarity LFP in SLM on the left, because the IPSCs produced by OLM cells were wider relative to those of BC/AACs, as shown in Figure $1 B$. On the right where $g_{s b}=5.75 \mathrm{nS}$, we observed a similar trend as for the example on the left where $g_{s b}=0.5$ nS with return currents dominating.

We would like to use our computational LFPs to determine how the different inhibitory cell types contributed to $\theta$ LFPs as recorded experimentally in the in vitro whole hippocampus preparation. As described above, our overall network model (Fig. 1A) was intended to capture an intrinsic $\theta$ rhythm in the CA1 region of the in vitro preparation. CA3 input was not required but local excitatory input which occurs on basal dendrites (Takács et al., 2012) did need to be included. To do this, we took advantage of previous modeling studies (Bezaire and Soltesz, 2013; Ferguson et al., 2015) as detailed in Materials and Methods. Including excitatory input would clearly affect resulting biophysical LFP outputs. Specifically, the LFP amplitude in SO might decrease even further in the presence of basal excitation as excitatory and inhibitory $\mathrm{BiC}$ inputs could cause mutual cancellations in this region. As return currents mostly exit close to the somatic region where the surface area is larger, the effect of basal excitation might be stronger in SO and SP since most of the current might have exited before reaching SR and SLM. In general, we expect there to be a range of possible LFP characteristics based on the above LFP computations done in the absence of basal excitation. We expect that the addition of excitatory input will influence the LFP in non-intuitive and nonlinear ways and the intuition developed above will be helpful in deciphering and explaining the contribution of the different cell populations to the LFP.

\section{Constraining synaptic conductances and connection probabilities between BiCs and OLM cells}

In this work, we focused mainly on OLM cells. The previous model network framework (Ferguson et al., 2015) was developed based on knowing that connections exist between BiCs and OLM cells (Leão et al., 2012). Given this, there were two pathways to consider for how OLM cells could influence ongoing intrinsic $\theta$ LFP rhythms. They can influence LFP output indirectly through disinhibition of proximal/middle dendrites of the PYR cell (OLMBiC-PYR, indirect pathway), or directly through inhibition 

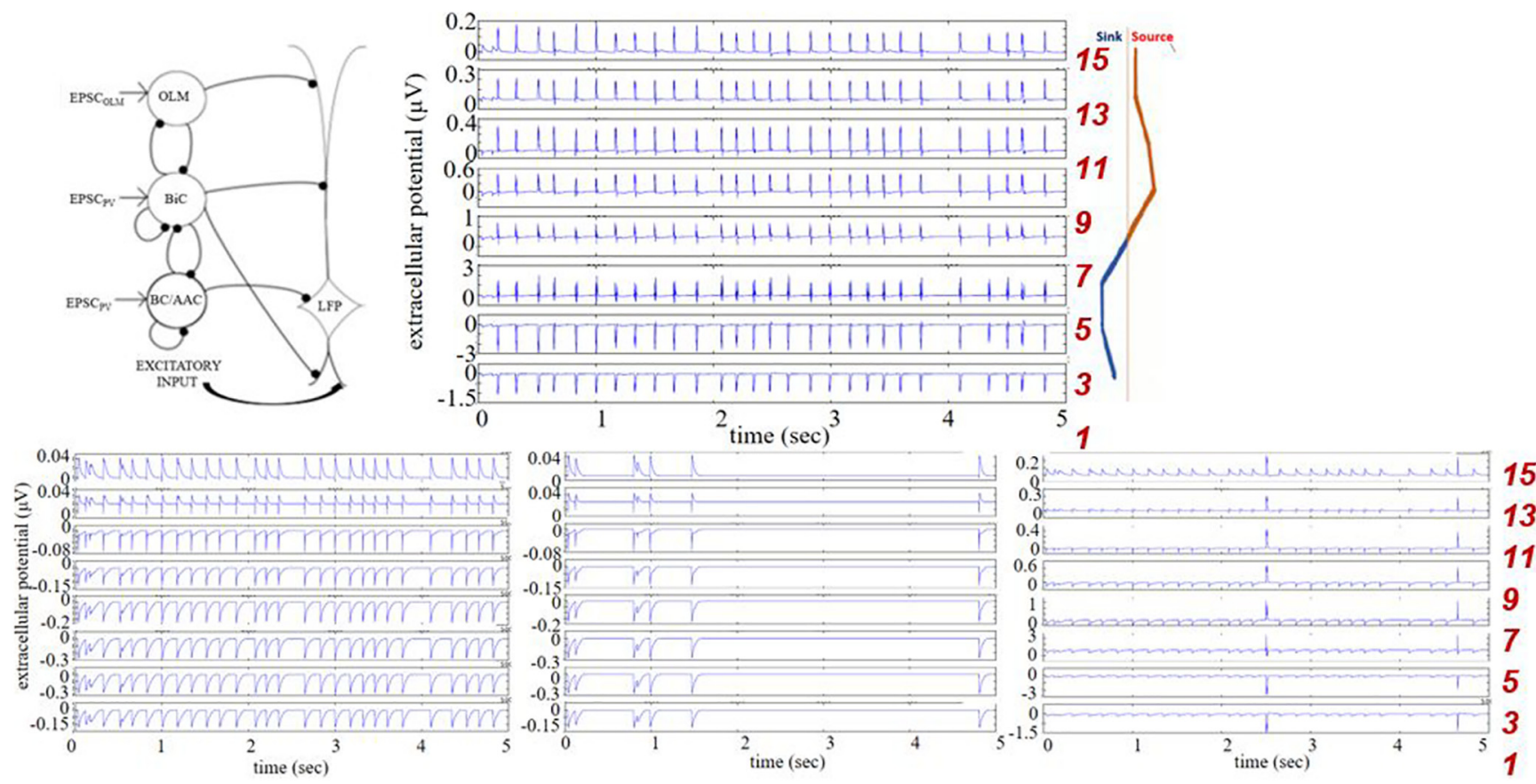

Figure 3. Example LFPs from selected and rejected parameter sets. Computed LFPs are shown across multiple layers. Top, Selected parameter set: $g_{s b}=6, g_{b s}=1.25 \mathrm{nS}$. Bottom, Rejected parameter sets (left to right): $g_{s b}=0.5, g_{b s}=0.75 \mathrm{nS} ; g_{s b}=0.5, g_{b s}=3.5$ $\mathrm{nS} ; g_{s b}=2.5, g_{b s}=1 \mathrm{nS} ; c_{s b}=0.21$ for all.

of distal, apical dendrites of the PYR cell (OLM-PYR, direct pathway). As shown above, many different LFP features can be exhibited in the absence of basal excitation (Fig. $2 A, B$ ). It is interesting to note that our biophysical LFP output did not necessarily exhibit $\theta$ frequencies, despite being driven by $\theta$ frequency EPSC inputs (Fig. 2Bii). This is because cancellations in the extracellular space between synaptic inputs and return currents can result in loss or even abolishment of the rhythm. This underscores the importance of modeling biophysical LFPs as the interaction of synaptic and return currents on the extracellular signal can strongly affect the resulting LFP frequency.

We proceeded to include basal excitation and performed a full set of computations for all connection probabilities $\left(c_{s b}\right)$ and synaptic conductances $\left(g_{s b}, g_{b s}\right)$. With these computed biophysical LFPs in hand, we did direct comparisons with experimental LFPs from the whole hippocampus preparation in vitro. Specifically, we classified each set of network parameters as selected or rejected based on whether our computed LFPs were able to reproduce two robust characteristics exhibited experimentally. These were: (1) the laminar polarity profile exhibited a single dipole with sinks in the basal dendrites and sources in the apical dendrites, and (2) the frequency of the LFP traces across all layers was in the $\theta$ frequency range. These characteristics are shown in Figure $1 A$. We note that our model setup in which experimentally derived $\theta$ frequency EPSCs were input to the inhibitory cells means that the LFP rhythm should have a $\theta$ frequency. However, as we have shown above, the resulting biophysical LFP frequency can be much less than $\theta$ due to synaptic and return current interactions and cancellations
(Fig. 2Bii). Specifically, the frequency of the EPSCs used from experiment is $\sim 5.8 \mathrm{~Hz}$. Thus, in enforcing the $\theta$ frequency on our LFP computations, it was only necessary to impose a lower bound. We used $3 \mathrm{~Hz}$ as the lower bound for $\theta$ range to be similar to experiment (Goutagny et al., 2009). We applied a peak detection on the LFP trace and used a threshold to avoid detecting baseline peaks. We required that the number of peaks be larger than 15 which given the 5-s LFP trace corresponds to 3 $\mathrm{Hz}$. In Figure 3, top, we show an example of computed LFPs across the different layers for a parameter set that was selected. The bottom of Figure 3 shows LFP outputs for three different parameter sets that were rejected incorrect polarities and frequencies are apparent. Note that ordinate resolutions were adjusted across the layers so that the frequency and polarity of computed LFPs can be readily seen in each layer in viewing.

Classifying each parameter set, we summarize our results in Figure 4, where selected parameter sets are shown in purple and rejected ones in yellow. We observed the following: for low $c_{s b}$, the plots have a checkered appearance since small changes in $g_{s b}$ and $g_{b s}$ caused the system to alternate between being selected or rejected. As $C_{s b}$ increased, there was a clearer separation in $\left(g_{s b}, g_{b s}\right)$ parameter space of selection or rejection. This was observed from $c_{s b}=0.19$ to $c_{s b}=0.25$. In this range, we considered the system to be robust as it was not very sensitive to synaptic conductance perturbations. However, for $c_{s b}=0.19,0.23$, and 0.25 , the selected parameter sets were quite narrow. As $c_{s b}$ was further increased, the checkered patterning returned. Note that the selected sets were mainly affected in one direction as $C_{s b}$ changed. That is, across $g_{s b}$ rather than $g_{b s}$ values. Further, we note 

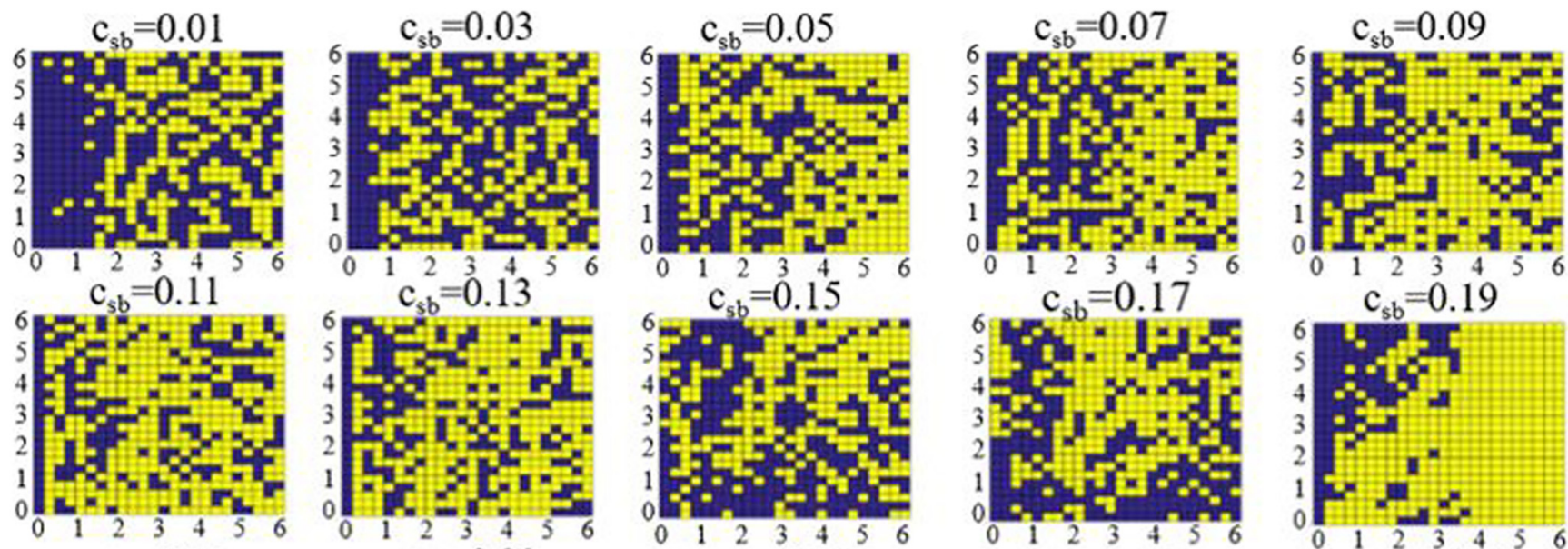

$$
\mathrm{c}_{\mathrm{sb}}=0.17
$$

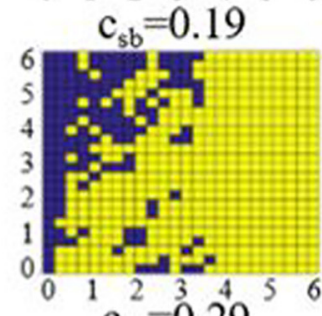

$\mathrm{c}_{\mathrm{sb}}=0.21$
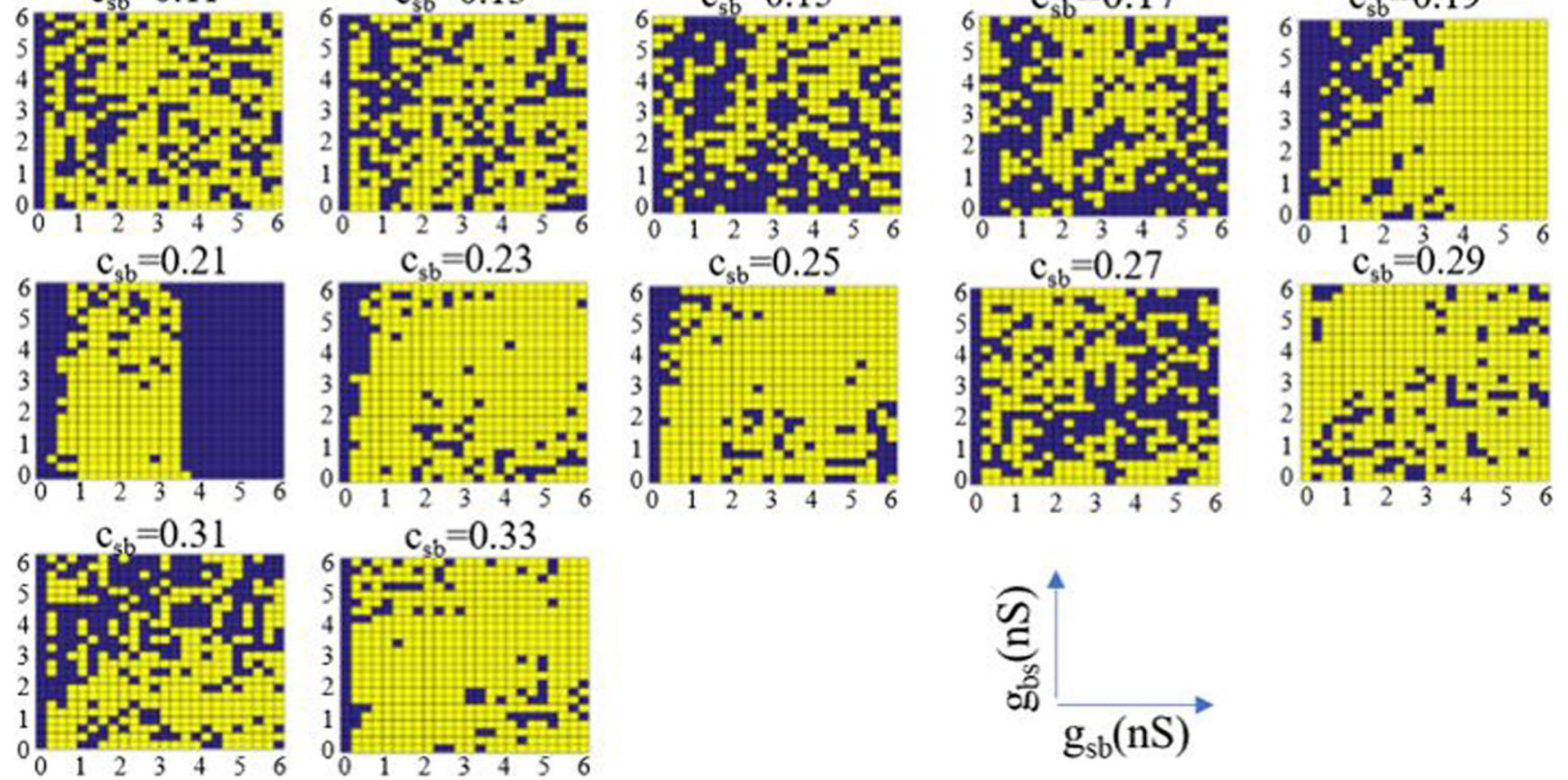

Figure 4. All selected and rejected parameter sets. Parameter sets are considered as selected (purple) if computed LFPs match LFPs from experiment in polarity and frequency (3-Hz lower bound). Otherwise, as rejected (yellow). A clear separation in parameter space occurs for $c_{s b}=0.21$.

that in doing this classification, it was more the polarity criteria rather than the frequency criteria of the LFP signal that delineated selected and rejected parameter sets. This is shown in Figure 5, where we did not apply any frequency bound or used different lower frequency bounds. While there was some change in selected and rejected parameter sets, they were minimal.

Since there is natural variability in biological systems, we assumed that sensitivity to small perturbations in parameter values is anathema to having robust LFP $\theta$ rhythms. Noting that the synaptic conductance resolution in our simulations was $0.25 \mathrm{nS}$, and that a minimal synaptic weight can be estimated as larger than this (see Materials and Methods), we considered that $\left(g_{s b}, g_{b s}\right)$ parameter sets that did not yield at least two complete, consecutive rows or columns of purple (selected) were inappropriate for the biological system. That is, variability that was less than a minimal synaptic weight would not make sense. Looking at this in Figure 4, we first note that there were never at least two complete purple rows for any $c_{s b}$, but there were cases of two or more complete purple columns, namely, $c_{s b}=0.03$ and 0.21 . However, a complete purple column for $g_{s b}=0$ was invalid since it is known that OLM to BiC connections exist Leão et al. (2012). Thus, $c_{s b}=0.03$ can be eliminated leaving $c_{s b}=$
0.21 as appropriate. For this connection probability, the transition from selected to rejected networks and vice versa strongly depended on $g_{s b}$ rather than on $g_{b s}$ values, revealing a more important role for the former. In summary, by directly comparing characteristics of our computed biophysical LFPs with those from experiment, we were able to constrain an appropriate connectivity as $c_{s b}=0.21$, with $g_{s b}$ values of 3.5-6 nS, and the full set of $g_{b s}$ values $\left(g_{s b} \neq 0, g_{b s} \neq 0\right)$. We will refer to this set of parameter values as the predicted regime. In Figure 6, we show example LFP responses across several layers for a set of parameter values from this predicted regime.

\section{OLM cells ensure a robust $\theta$ LFP signal, but minimally affect LFP power, and only through disinhibition}

In continuing our analysis, we now focused on constrained parameter sets as determined above which we termed the predicted regime $\left(c_{s b}=0.21\right)$. We decomposed the signal to be able to examine the contribution of the interneuron subtypes to the power of the LFP. We separated our interneuron subtypes into two groups: PV subtypes which are BC/AACs and BiCs, and SOM subtypes which consist of the OLM cells here. These two groups were represented by distinct mathematical mod- 

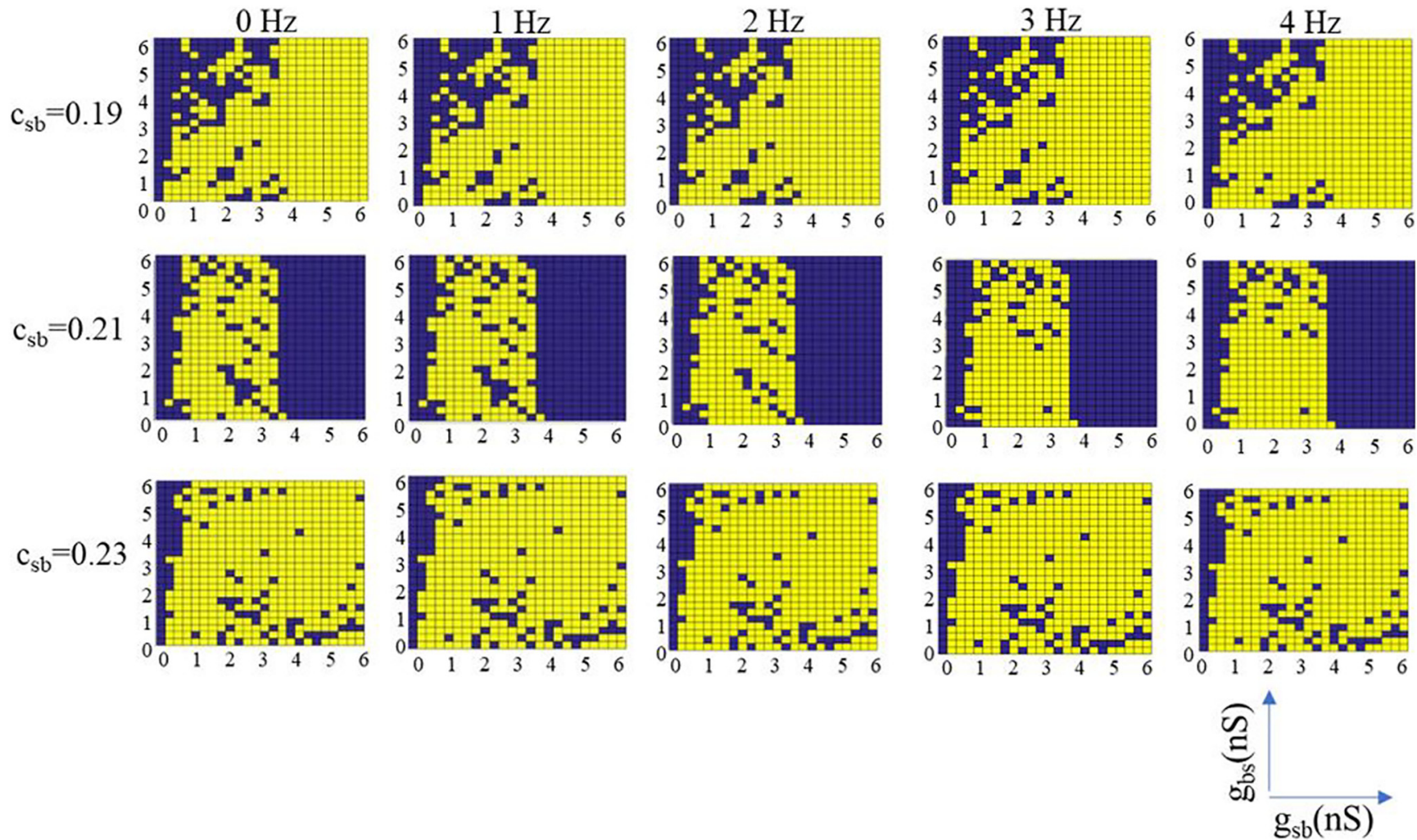

Figure 5. Selected and rejected parameter sets using different lower frequency bounds. The different frequency bounds used are shown at the top of each column and only three different $c_{s b}$ values are shown. Note that we use $3 \mathrm{~Hz}$ as the frequency bound in Figure 4.

els of fast-firing PV and SOM inhibitory cells based on whole-cell recordings from the whole hippocampus preparation (Ferguson et al., 2015). We performed spectral analyses of our computed LFPs and used the peak amplitude as a measure of the power of the $\theta$ network activity. The peak power was computed for each of the 15 electrodes (i.e., all layers), and we plotted the maximum value from all of the layers in the color plots of Figure 7. This is illustrated on the right of Figure $7 A$. We first simulated the spectral LFP power when all presynaptic inhibitory cell populations were present. As shown in Figure $7 A$, a robust power feature emerged. When all presynaptic origin populations were present, the predicted regime shown in purple in Figure 6, produced LFP responses
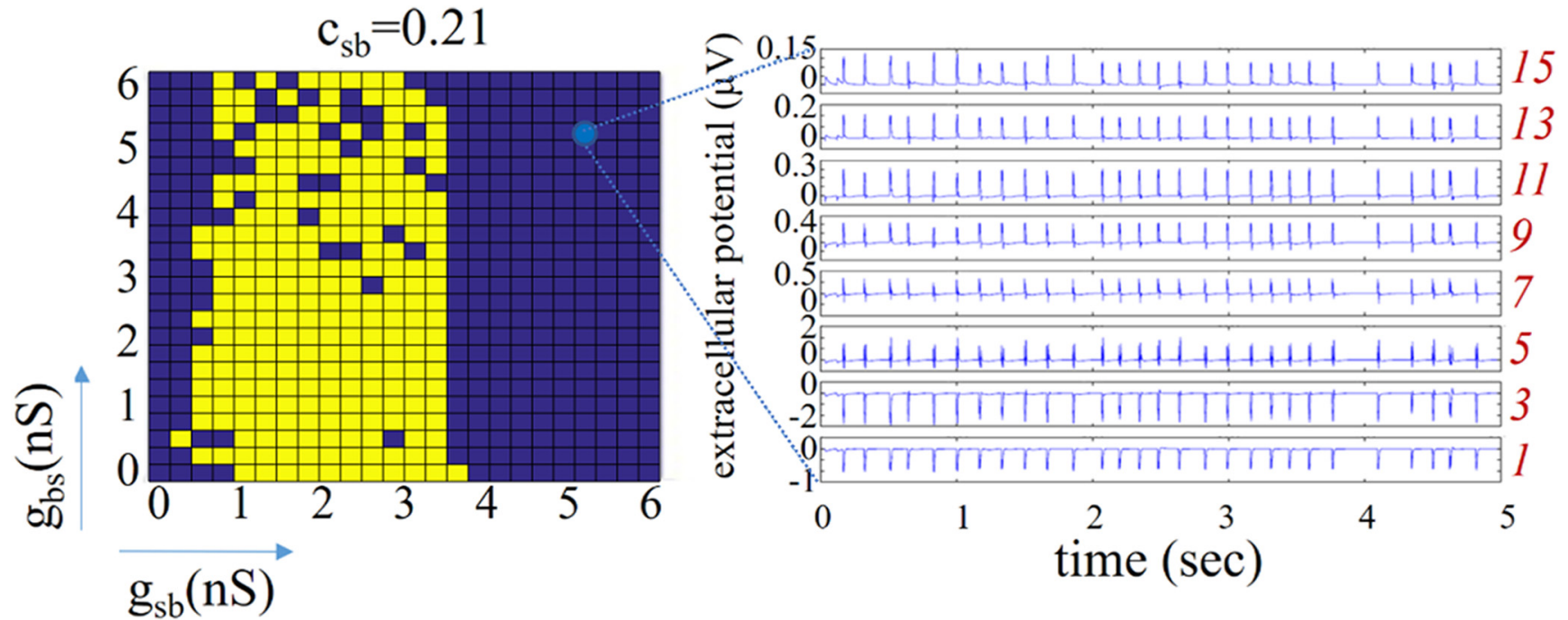

Figure 6. Predicted regime. For $c_{s b}=0.21$, selected parameter sets (purple) include $g_{s b}$ values of $3.5-6 \mathrm{nS}$, and all $g_{b s}$ values. Rejected sets are in purple. On the right are LFP traces from 8 electrodes for a parameter set of $g_{s b}=4.75, g_{b s}=4.50 \mathrm{nS}$. 


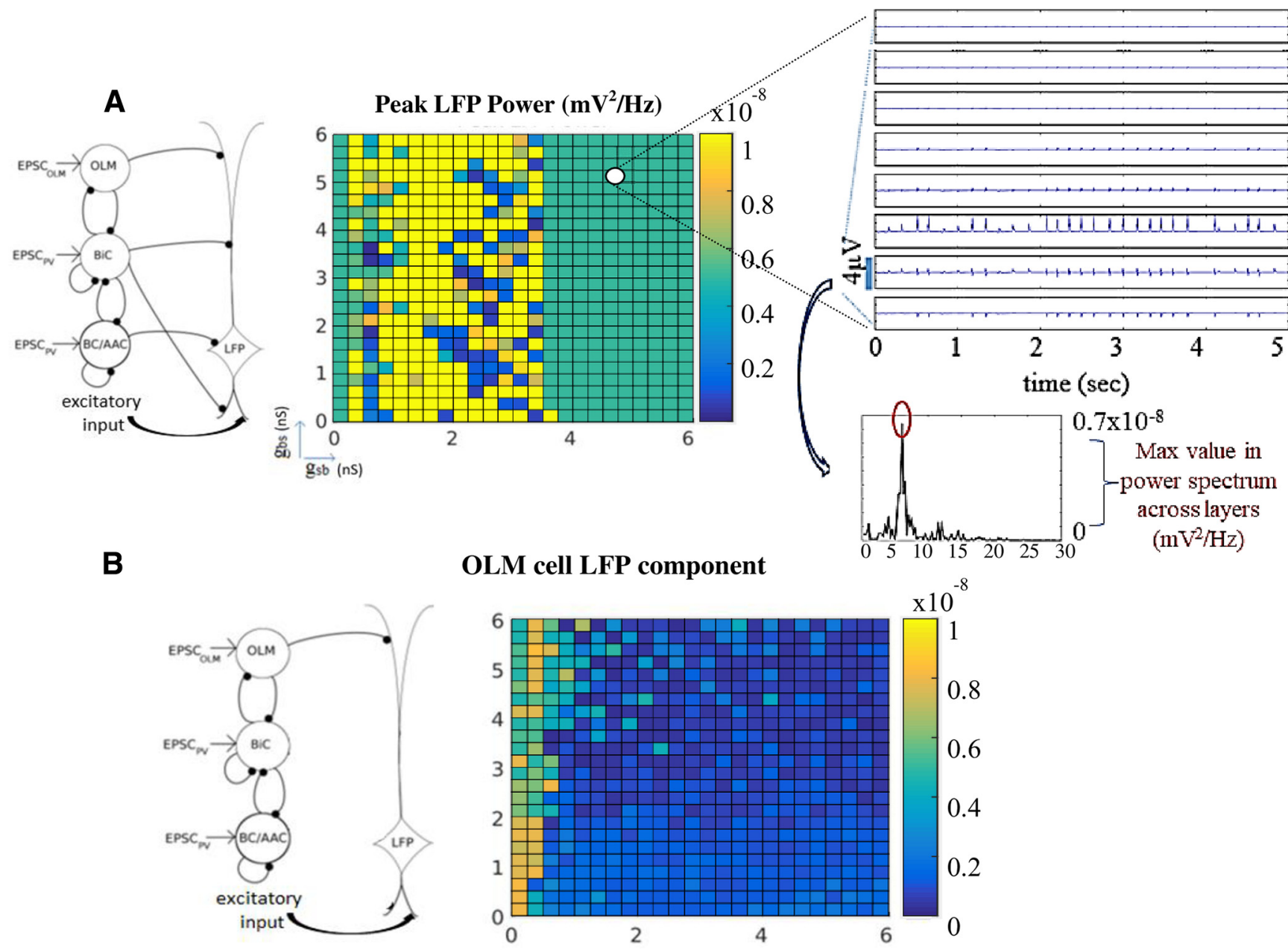

C

\section{PV cell LFP component}
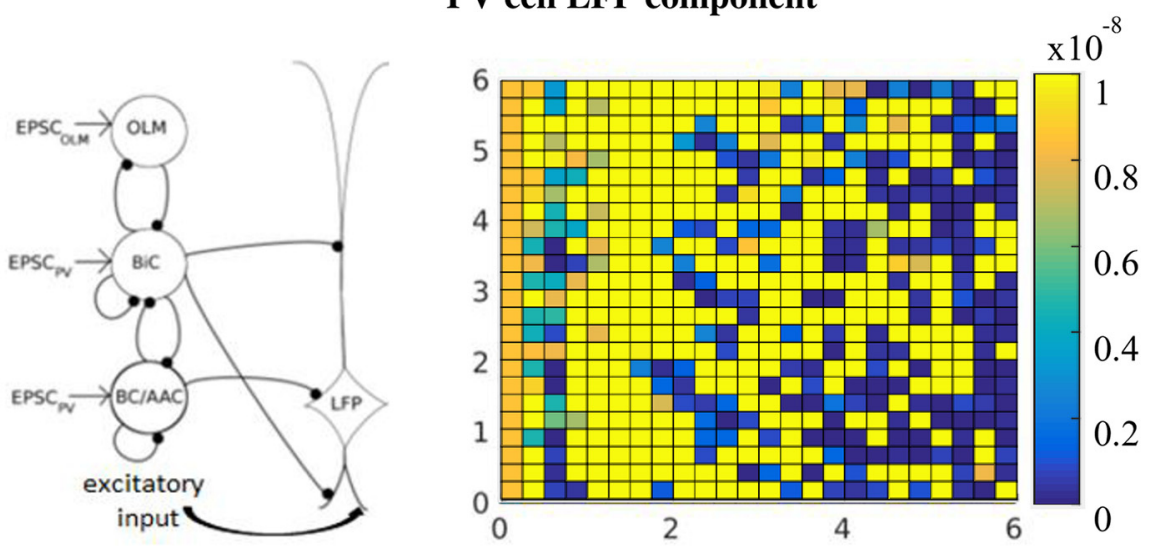

Figure 7. Decomposition of the LFP signal. A, All presynaptic cell populations are present. $\boldsymbol{B}$, Only OLM cells are present. $\boldsymbol{C}$, Only $\mathrm{BiCs}$ and BC/AACs are present. Schematics on the left show the cell populations projecting to the PYR cell. Computations are done across $g_{s b}$ and $g_{b s}$ parameter values where $c_{s b}=0.21$. For each parameter set, LFPs are computed across all layers and the power spectrum is computed for each layer. The maximum power across all layers is taken as the peak power and given in the color plot. Computation is illustrated to the right of $\boldsymbol{A}$ (see text for details).

whose power showed minimal variability. This is an interesting observation on its own, as the power of the LFP varied little across hippocampus preparations (Goutagny et al., 2009). Thus, our predicted regime satisfied another characteristic of experimental LFPs. We note that outside of the predicted regime, the LFP output showed much more variability, and the LFP frequency across layers was not necessarily $\theta$, as it was not part of the selected parameter sets. For completeness, we show peak power computations that were done for all connectivities in Figure 8. 

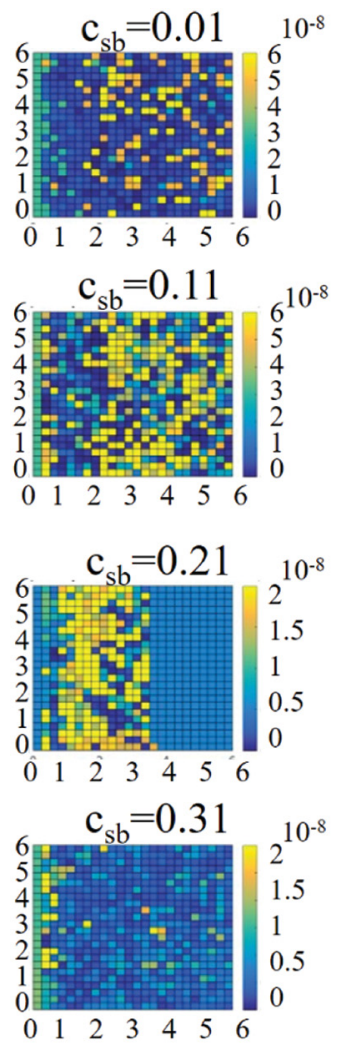
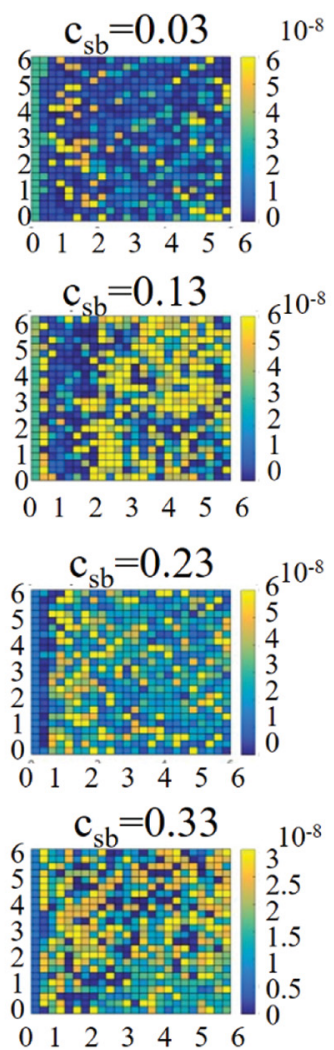

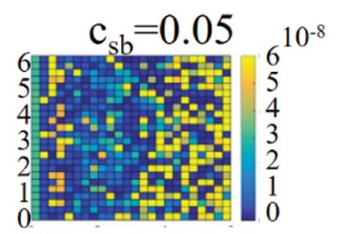

$\begin{array}{lllllll}0 & 1 & 2 & 3 & 4 & 5 & 6\end{array}$
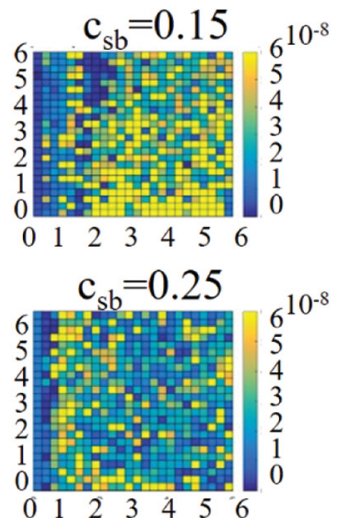

$\begin{array}{lllllll}0 & 1 & 2 & 3 & 4 & 5 & 6\end{array}$

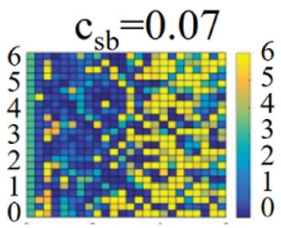

$\begin{array}{lllllll}0 & 1 & 2 & 3 & 4 & 5 & 6\end{array}$
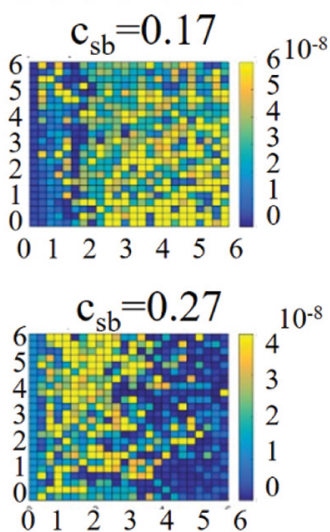

$\begin{array}{lllllll}0 & 1 & 2 & 3 & 4 & 5 & 6\end{array}$

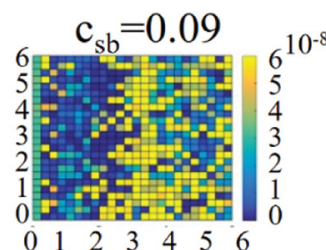

3456
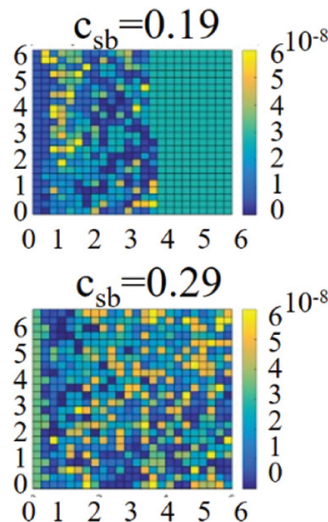

$\begin{array}{lllllll}0 & 1 & 2 & 3 & 4 & 5 & 6\end{array}$

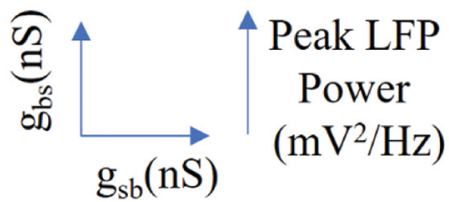

Figure 8. Peak power for all conductances and connectivities. Note that the color scale bars are not the same for all the plots. The plot for $c_{s b}=0.21$ corresponds to Figure $7 A$.

To examine the role of presynaptic origin populations on the LFP we decomposed the signal by selectively removing OLM to PYR cell connections or PV to PYR cell connections and then computing and plotting the peak power as described above. Selective removal of synapses from PV cells to the PYR cell yielded an LFP response whose presynaptic origin population was due to the OLM cell population. The resulting LFP power was low and depended weakly on $g_{b s}$ (Fig. 7B). This showed that OLM cells minimally contributed to the signal power as a presynaptic origin population. Viewing this from a broader perspective, these results indicated that disinhibition of non-distal apical dendrites via an indirect (OLM-BiC-PYR) pathway played a much larger role relative to a direct (OLM-PYR) pathway in producing the LFP power. Along the same lines, disinhibition of distal dendrites through a BiC-OLM-PYR pathway thus did not have much of an effect on LFP power. Figure $7 C$ shows the result when we selectively removed the synapses from OLM cells to the PYR cell to yield an LFP response whose presynaptic origin was the PV cell population. It is clear from the magnitude of the signal powers in Figure $7 C$ relative to Figure $7 B$ that the $\theta$ power was indeed mainly due to the component from PV cells rather than from OLM cells. Interestingly, the previously seen robustness when all presynaptic cell populations were present (Fig. 7A) was now lost. To quantify all of this, we computed the mean and SD of the peak powers in the predicted regime for Figure $7 A-C$. Respectively, they were (mean, SD) in units of $m V^{2} / \mathrm{Hz}:\left(5.1 \times 10^{-9}, 1.7 \times 10^{-23}\right),\left(9.7 \times 10^{-10}, 5.6 \times\right.$ $\left.10^{-10}\right),\left(2.6 \times 10^{-8}, 3.8 \times 10^{-8}\right)$. When all of the cell populations were present, there was minimal variability, and when the PV cell populations were removed, the average power decreased five-fold and there was some variability. However, when only PV cell populations were present, there was an increase in the average power and the variability was large. It seems clear that OLM cells did not contribute much to the average LFP power but removing their inputs prominently affected the robustness of the LFP signal. Therefore, we propose that OLM cells have the capacity to regulate robustness of LFP responses without affecting the average power.

In a recent study, Amilhon et al. (2015) showed that SOM cells (putative OLM cells) did not appear to play a prominent role in the generation of intrinsic LFP $\theta$ rhythms since there was only a weak effect on LFP $\theta$ power when they optogenetically silenced SOM cells. Our results are in agreement with this observation. As shown in Figure 7B, the contribution of OLM cell inputs to the LFP power was small. To make a more accurate comparison with Amilhon et al. (2015)'s OLM cell optogenetic silencing experiments, we compared the power of the LFP in the predicted regime in Figure $7 A$ (mean value of $5.1 \times 10^{-9} \mathrm{mV}$ ${ }^{2} / \mathrm{Hz}$ ) with the power of the LFP in Figure $7 \mathrm{C}$ for $g_{s b}=0$ and $g_{b s}=0$ when OLM cell to PYR cell connections were also removed $\left(8.5 \times 10^{-9} \mathrm{mV} 2 / \mathrm{Hz}\right)$. They were clearly comparable. It is interesting to note that it was already apparent from Figure $7 A$ that OLM cells minimally affected LFP power. Consider that for the parameter regime of $g_{s b}=0$ and across all $g_{b s} s$, the LFP power magnitude 
A

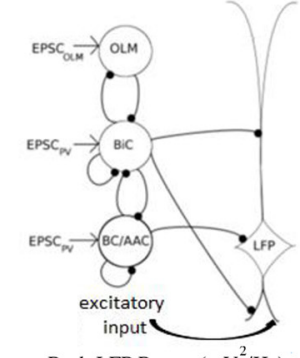

Peak LFP Power $\left(\mathrm{mV}^{2} / \mathrm{Hz}\right)$

PV cell LFP component

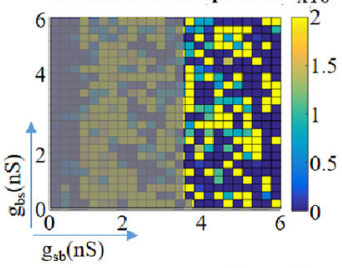

B

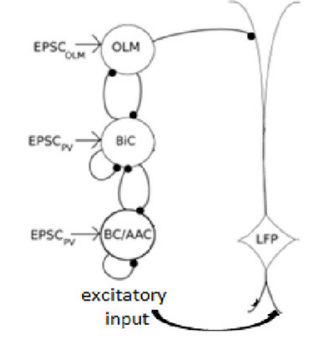

OLM cell LFP componen

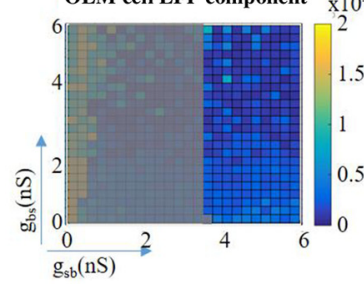

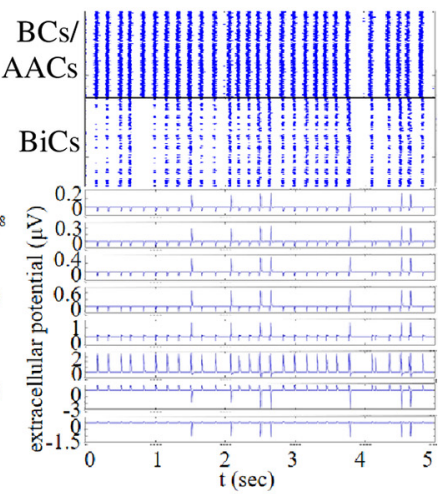
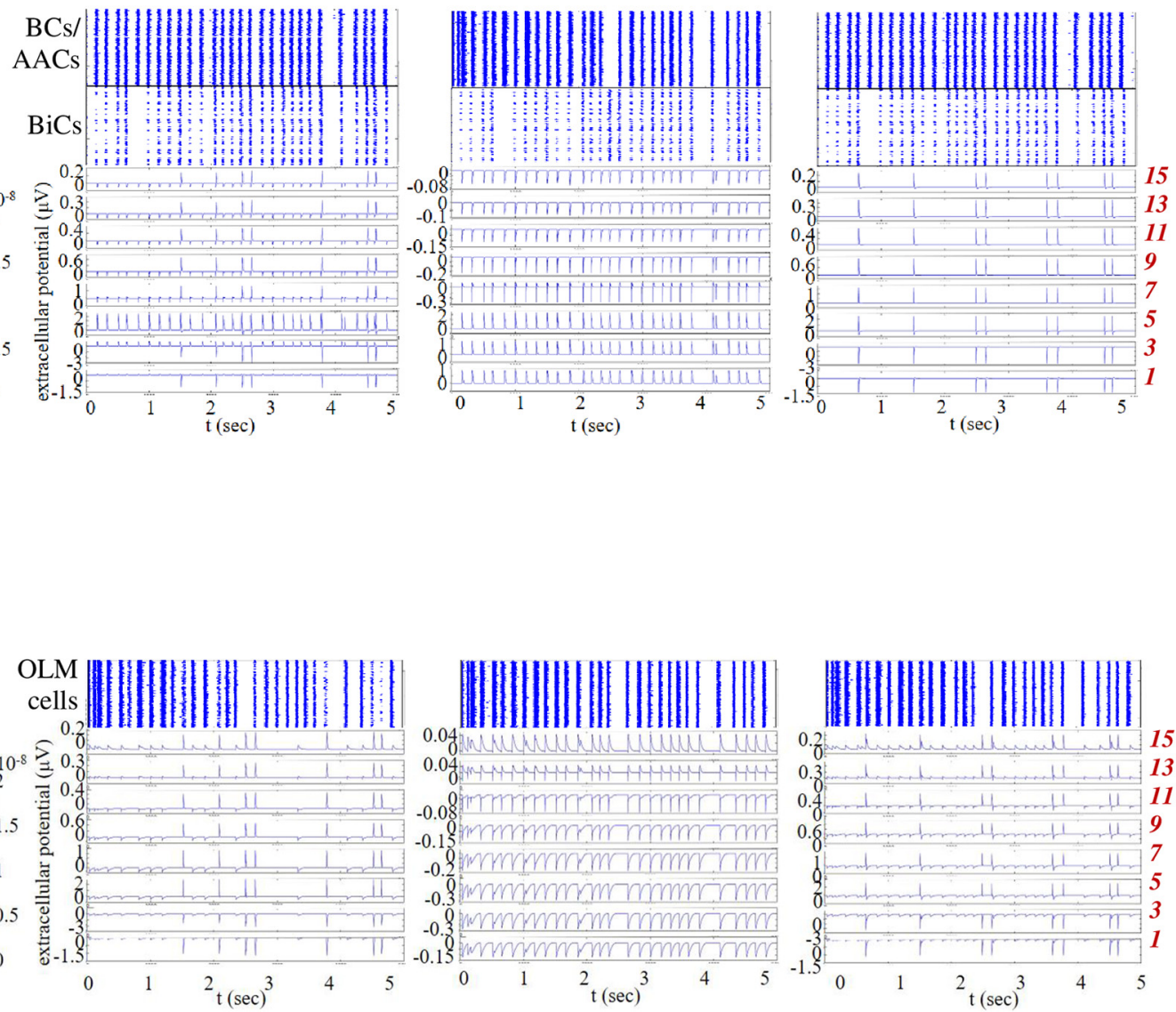

Figure 9. LFP pattern examples in predicted regime when only either PV or OLM cell populations are present. Peak power color plots as in Figure 7 are shown but with a different color resolution. A gray overlay is added to the plots to emphasize the predicted regime. Three examples of LFP responses $(5 \mathrm{~s})$ across the different layers are shown to illustrate the different patterns observed. For each example, spike rasters for the particular example are shown for PV cells (BiCs and BC/AACs) or OLM cells. A, PV cell LFP component. $\boldsymbol{B}$, OLM cell LFP component. Parameter values for left, middle and right columns are, respectively, $\left(g_{s b}, g_{b s}\right)=(5,2.75),(5.5,0.5)$, $(5.75,1) \mathrm{nS}$.

was the same $\left(5.1 \times 10^{-9} \mathrm{mV}^{2} / \mathrm{Hz}\right)$ as the average power of the predicted regime in Figure $7 A$. In this $g_{s b}=0$ parameter regime, OLM cell to $\mathrm{BiC}$ connections were not present but the OLM cell to PYR cell connections were still present so that OLM cells could still contribute to the LFP response via a direct OLM-PYR pathway. Given that the power did not change indicates that any LFP power contribution due to OLM cells occurred mainly via the indirect OLM-BiC-PYR pathway. Overall, our results show that OLM cells did participate but in such a way that their presence would be unnoticed if one were only measuring LFP power.

To gain insight into how OLM cells affected the robustness of the LFP signal, we further examined what was revealed with our LFP decompositions. We observed that with PV or OLM cells removed, the impaired LFP output could be grouped into certain categories based on their laminar LFP profiles. In Figure 9, we show the peak power plots for the PV cell (Fig. 9A) and OLM cell (Fig. 9B) decomposition components in which the non-predicted regime was overlaid with gray. For each component, we show three examples of the characterized LFP profiles identified in the groupings. Raster plots that corresponded to each cell population are shown above the examples in the figure. It is evident that the different LFP patterns cannot be intuited from the raster plots alone. These examples illustrate the various cases of impaired LFP responses that occurred when OLM or PV cell connections to the PYR cell were removed.

For the middle LFP response examples (low $g_{b s}$ and high $g_{s b}$ ) of Figure 9, we note that OLM cells and $\mathrm{BC} /$ AACs had maximal activities and BiCs had minimal activities (Fig. 2C). Thus, synaptic current influences were obvious at the layers where OLM or BC/AACs contact, and return currents at other layers. Inappropriate polarity across the layers was manifest. This pattern of impaired LFP response occurred in about a quarter of the PV cell LFP component parameter sets, and in less than half of 
the OLM cell LFP component parameter sets. For the PV cell LFP component, most of the other parameter sets yielded LFP responses in which there was no rhythm, as shown in the right example of Figure 9A. Interestingly, in the rest of the cases (less than a third), there was a loss of rhythmicity in all layers except for the somatic layer as illustrated in the left example. These patterns show that there was an ongoing "battle" between basal excitation and PV cell inputs that can yield a wide range of LFP powers from low (no rhythm, right example) to high (left and middle examples). For the majority of the OLM cell LFP component parameter sets, there was a loss of rhythmicity as shown in the left and right examples of Figure $9 B$. From the temporal profile and polarity, it was clear that the high amplitude LFP peaks were due to basal excitatory inputs. For larger $g_{b s}$ values, OLM cells were less active (Fig. 2C) and LFP responses across the layers became dominated by peaks due to basal excitation rather than synaptic and return currents due to OLM cells. Overall, cancellations and rhythm loss occurred due to interactions between OLM cells' synaptic and return currents and excitatory inputs. As summarized in the peak power plots of Figure $7 C$ or Figure $9 A$, PV cell inputs alone were not capable of sustaining the robustness throughout the predicted regime and the impaired LFP signals showed a large variability. With OLM cell inputs alone, there was low LFP power either because of loss of rhythmicity or because of low amplitude rhythms (Fig. 7B or Fig. $9 B$ peak power plots).

\section{With and without basal excitation}

As one might expect, including basal excitation to incoming inhibitory inputs from different cell populations added to the complexity of untangling nonlinear, interacting components producing the LFP. We relied on our developed intuition when basal excitation was not included (Fig. 2A,B) and our LFP decompositions to help reveal the different roles that OLM cells and PV cells might play in LFP $\theta$ rhythms. Specifically, we can understand that the loss of LFP rhythm at some layers likely occurred because of having a "balance" of synaptic and return currents for various conductance values leading to LFP rhythm cancellation or an inappropriate negative polarity domination (Fig. 2Aiii,Biii). Thus, in finding that the LFP power was a robust feature in the predicted regime of synaptic conductance and connection probabilities, we were able to understand that it was critically the OLM cell population that brought about this robust feature. However, this robust feature was apparent only when basal excitation was included. This is clearly visualized in Figure 10 , where we plot the peak power color plots with and without basal excitation when all cells were present or with only OLM cell or PV cell LFP components. Removal of basal excitatory inputs in the case when all cells were present (Fig. 10, top) led to a loss of robustness. The mean and SD in the predicted regime without basal excitation was $6.2 \times 10^{-9}$ and $8.0 \times 10^{-9} \mathrm{mV}^{2} / \mathrm{Hz}$, respectively. While the mean was comparable to when basal excitation was present, the SD was much larger (see values with basal excitation above). Coactivation of inhi- bition and excitation was clearly important for this robust feature to emerge.

From the LFP decompositions and different LFP patterns expressed (Fig. 7B), and OLM cell activities (Fig. 2C), we can understand that the contribution of OLM cells was more dependent on $g_{b s}$ than $g_{s b}$ with the basal excitation affecting the peak power robustness more for larger $g_{b s}$ values. This was apparent in the color variation of the plots of the OLM cell LFP component in Figure 10, middle. It was larger with basal excitation (left) than without basal excitation (right) for larger $g_{b s}$ values. This was reflected in the mean and SD without basal excitation $\left(5.2 \times 10^{-10}\right.$, $2.2 \times 10^{-10} \mathrm{mV}^{2} / \mathrm{Hz}$ ) that was smaller than with basal excitation (see values with basal excitation above). With only the PV cell LFP component, the LFP $\theta$ rhythm was disrupted as the interactions between basal excitation and PV inhibitory inputs were missing the OLM cell inputs. Specifically, the mean and SD without basal excitation was $\left(8.0 \times 10^{-9}, 1.1 \times 10^{-8} \mathrm{mV}^{2} / \mathrm{Hz}\right)$ which was smaller than with basal excitation (see values with basal excitation above). In essence, the inclusion of basal excitation can be considered as "adding" to the magnitude and variance of the LFP power when OLM cells or PV cells were examined separately. In combination, a synergistic effect between inhibition and excitation occurred to generate a robust regime, a mean power with minimal variance. From Figure $2 C$, it can be seen that the PV cells (BC/AACs and BiCs) had activities that were more dependent on $g_{s b}$ than on $g_{b s}$, and that BC/AACs were relatively more active than BiCs in the predicted regime. Thus, at larger $g_{b s}$ values when OLM cells were less active, BC/AACs would contribute more to keeping a synergistic balance with the basal excitation.

\section{LFP power across layers}

As illustrated in Figure $7 A$, the color peak power plots are the power in the layer (particular electrode) where the power was maximal. To fully express this, we plotted the maximum LFP power across the dendritic tree for all parameter sets in the predicted regime. This is shown in Figure $11 A$ with insets showing the same for the OLM cell (top) and PV cell (bottom) LFP components. From this, we see that the maximum LFP power was recorded at electrode 4, and that with only the OLM cell component, the power was distributed more widely and with only the PV cell component, more narrowly focused around the soma. This thus shows that the two populations differentially influenced the location of LFP maxima. That the LFP power showed no discernible variability when all the cell populations were present, and that there was clear variability when not all of the cell populations were present is obvious in this Figure $11 \mathrm{~A}$. We did several additional sets of simulations to explore whether changes in the synaptic weights on the PYR cell would affect whether the robust power feature in the predicted regime would still be present. In all the simulations presented so far, we used synaptic weights that did not bias the effect of one cell population type over the other based on their synaptic input location. So, for example, OLM cell inputs that were the furthest away from the soma had the largest synaptic 
With basal excitation

A

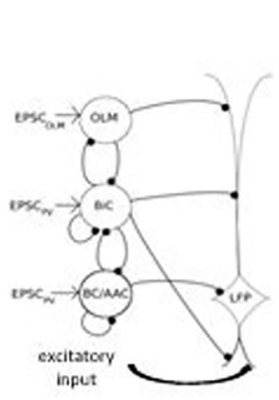

B

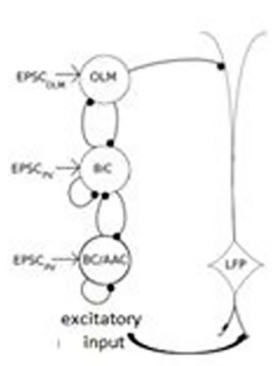

C
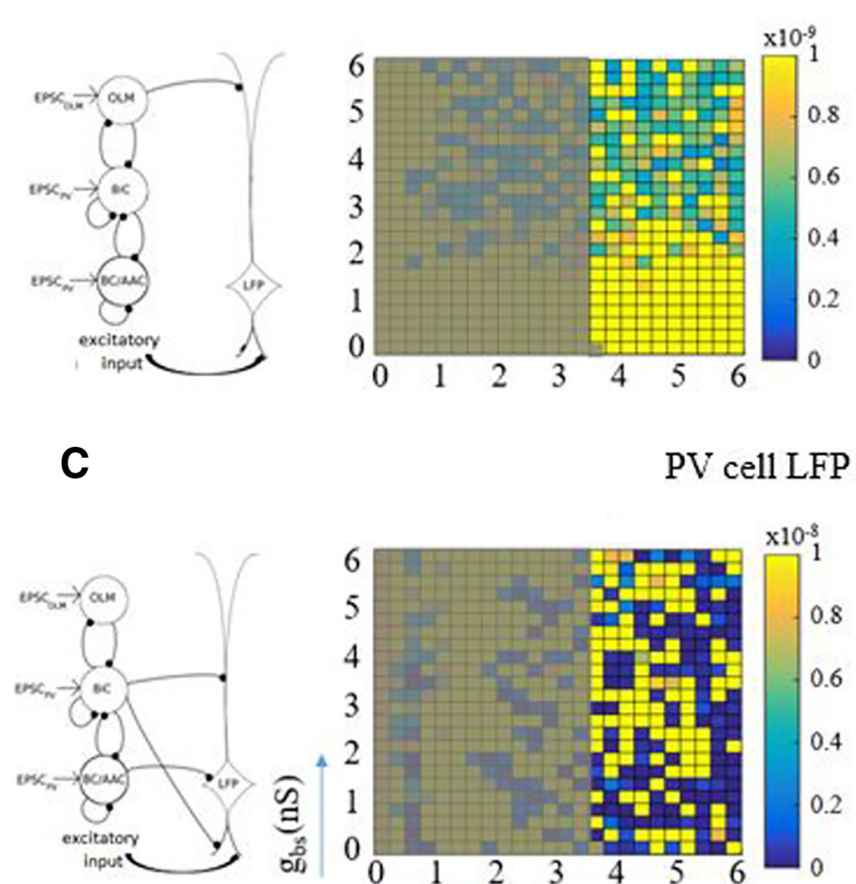

All cell populations
Without basal excitation
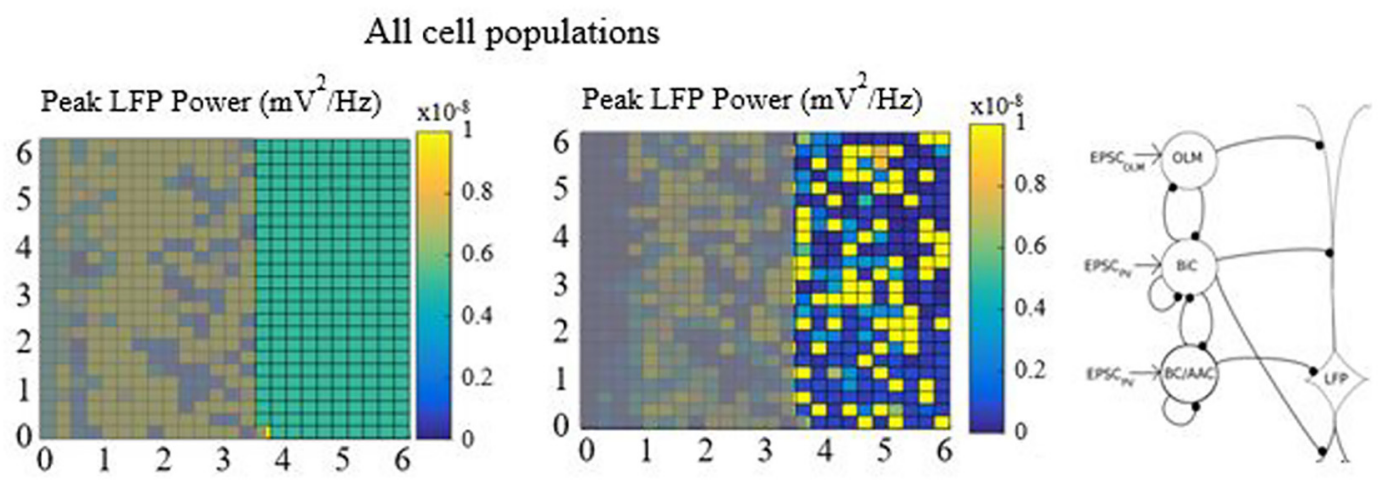

\section{OLM cell LFP component}
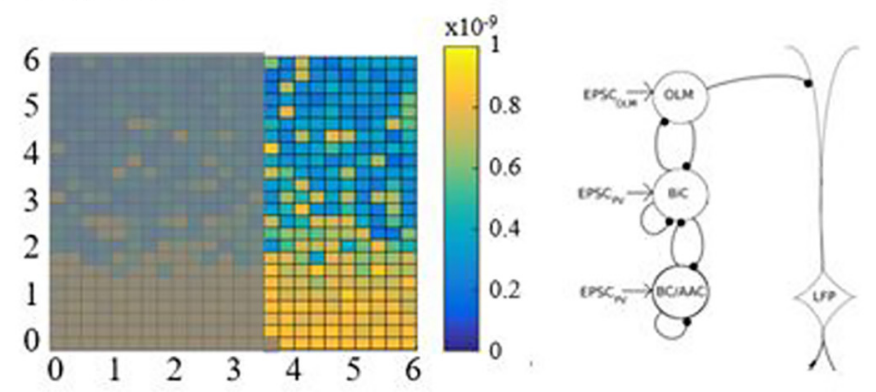

PV cell LFP component
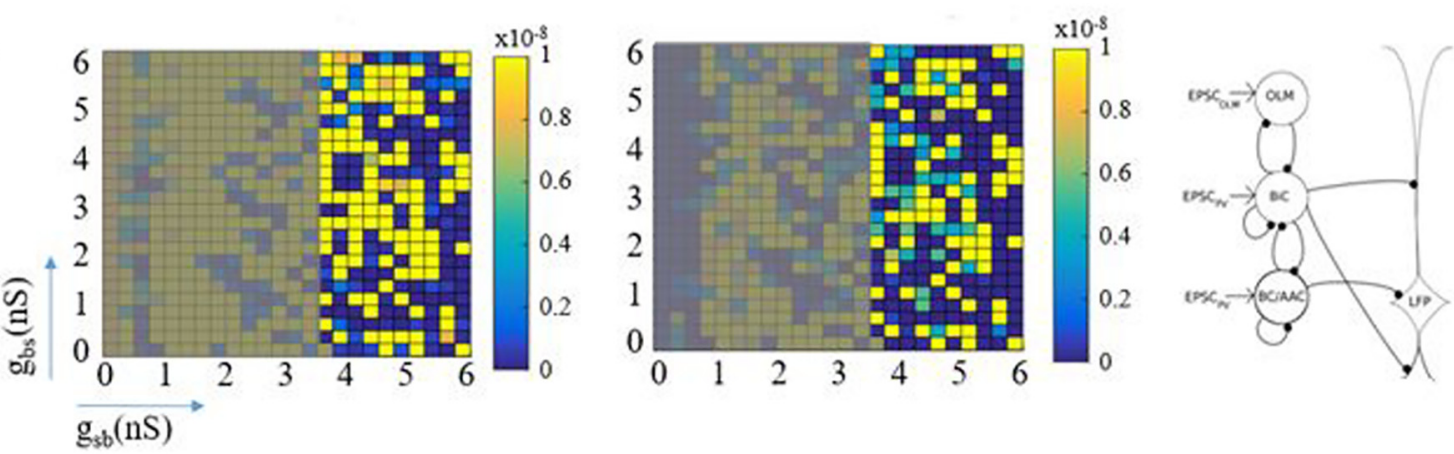

Figure 10. Peak power plots with and without basal excitation. The color plots represent peak power as described in Figure 7 and with a gray overlay as in Figure 9. Note that different color resolutions are used here to facilitate comparison for particular cell populations (i.e., any row). With and without basal excitation is shown on the left and right columns, respectively. Top, All cell populations. Middle, OLM cell LFP component. Bottom, PV cell LFP component.

weight. In doing this, we were following what was done previously in Ferguson et al. (2015) who used "unbiased" synaptic weights as well as using the same synaptic weight for all of the cell types. In using the same synaptic weight for all the cell types, we found that the robust power feature in the predicted regime remained (data not shown).

As described and shown above, it was already clear that OLM cells via a direct OLM-PYR pathway minimally contributed to the LFP $\theta$ power. To show this directly, we did several, additional simulations where we changed the synaptic weight from OLM cells to the PYR cell. As an example, in Figure 11B, we show that increasing the synaptic weight by almost an order of magnitude decreased the peak power by only $\sim 20 \%$.

\section{Estimating the number of PYR cells that contribute to the LFP signal}

It is challenging to know how many cells contribute to an extracellular recording. The hippocampus has a regular cytoarchitecture with a nearly laminar, stratified structure of PYR cells (Andersen et al., 2006). This arrangement together with PYR cells being of similar morphologies and synaptic input profiles means that we can assume that any given PYR cell will generate a similar electric field leading to an additive effect in the extracellular space with 
A

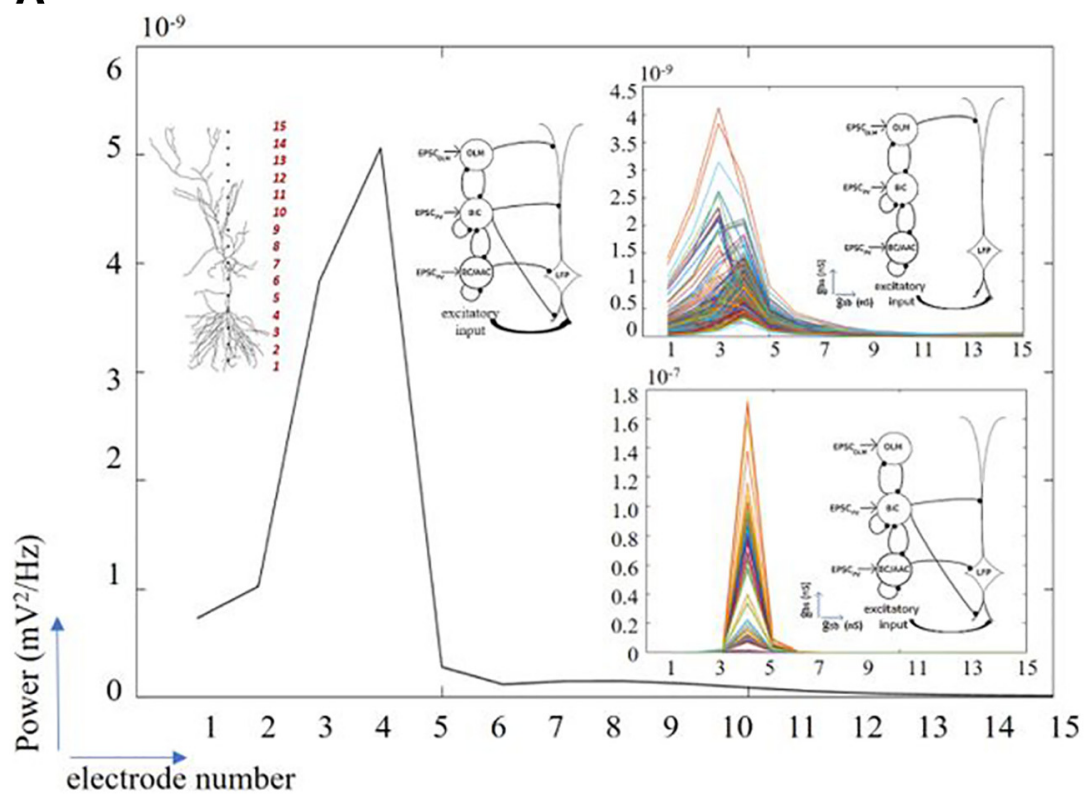

B

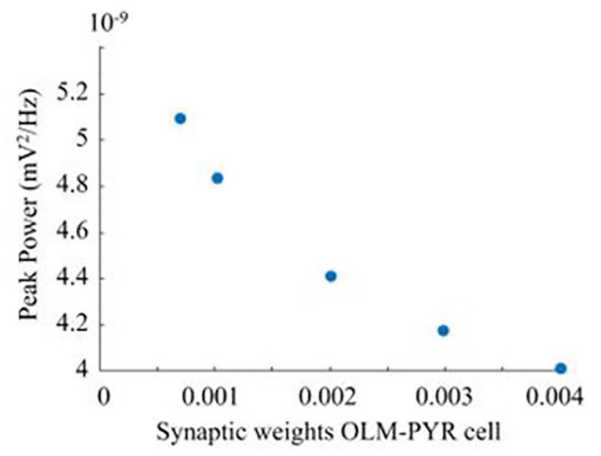

Figure 11. Laminar power and peak power changes with changing synaptic weights. $\boldsymbol{A}$, Computed power at the different electrode locations to show laminar power distribution, for all sets of parameter values in the predicted regime. Top inset, Laminar power for OLM cell LFP component. Bottom inset, Laminar power for PV cell LFP component. Schematics shows the PYR cell model with the 15 extracellular electrodes and the different network configurations. $\boldsymbol{B}$, Changing the synaptic weight from the OLM cells to the PYR cell does not lead to much change in the peak power, as illustrated by the peak power at electrode 4 . Parameter values: $g_{s b}=5.25$, $g_{b s}=5.00 \mathrm{nS}$. Synaptic weights of $0.00067,0.001,0.002,0.003$, and $0.004 \mu \mathrm{S}$ are shown.

multiple cells in resulting LFP dipole recordings. Further, for the in vitro intrinsic $\theta$ LFP generation being considered in this work, the focus can be justified to the couple of synaptic pathways that we explored, and incoming inputs were synchronized amplifying the additive effect.

To estimate how many PYR cells contributed to an extracellular LFP recording in the in vitro whole hippocampus preparation, we defined the "spatial reach" of the LFP as the radius around the electrode where the LFP amplitude was decreased by $99 \%$. Using our biophysical computational LFP models with parameter values taken from the predicted regime, we found that the spatial reach is $300 \mu \mathrm{m}$ as measured extracellularly close to the soma since the LFP decreased from 10,000 to $100 \mathrm{nV}$ within this radius. This is shown in Figure 12, where the dotted arrow represents this radius. Therefore, from a "neuron-centric" approach the LFP declined to $1 \%$ of its original power within $300 \mu \mathrm{m}$. From an "electrode-centric" point of view this means that if we were to place an electrode extracellularly to the soma of a given neuron then that electrode would pick up signal from neurons within $300 \mu \mathrm{m}$ as any neuron $300 \mu \mathrm{m}$ further away would contribute to the recorded signal by $<1 \%$ of its maximum power. To estimate the number of cells present within this spatial extent we turned to literature. Taking advantage of detailed quantitative assessment and modeling done by Bezaire and colleagues (Bezaire and Soltesz, 2013; Bezaire et al., 2016), there are $\sim 311,500$ PYR cells in a volume of 0.2 $\mathrm{mm}^{3}$ of "SP" tissue (see model specifics in Bezaire et al., 2016, their Fig. 1). Given our spatial reach radius estimate, a cylindrical volume of SP would be $0.014 \mathrm{~mm}^{3}$ or $\sim 7 \%$ of the total number of PYR cells which is $\sim 22,000$. In this

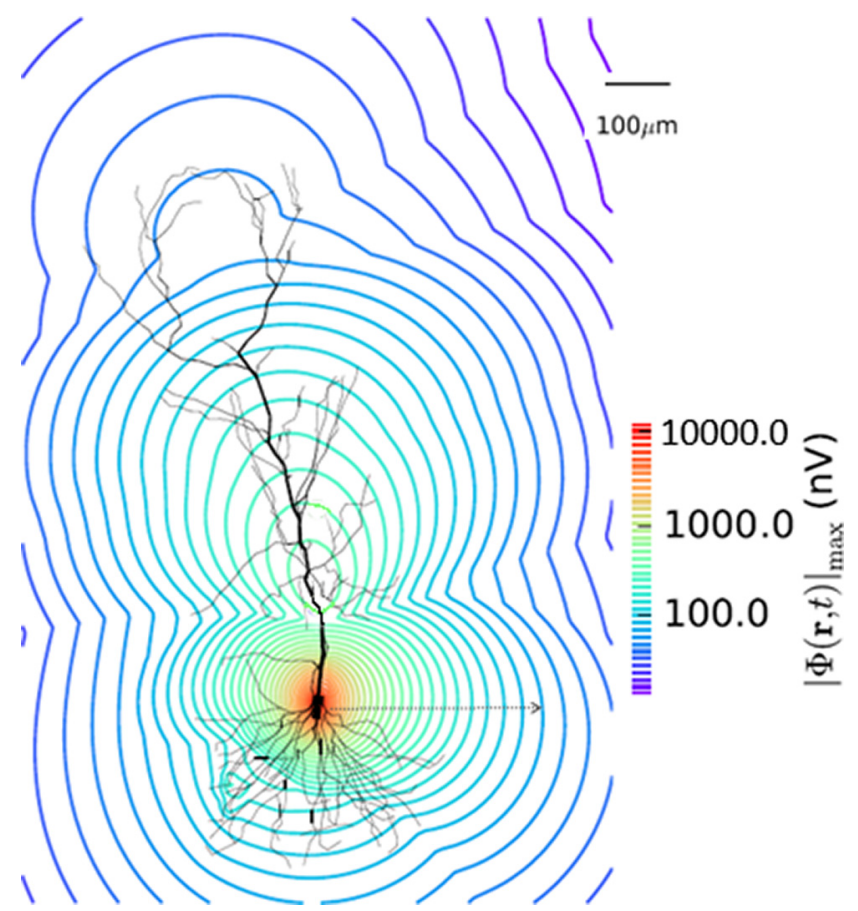

Figure 12. Spatial attenuation. We estimated the spatial extent of the generated LFP using our models. PYR cell model morphology is shown with calculated signal decrease from an electrode positioned near the cell soma. The dotted arrow shows the extent of the spatial reach of the signal that is taken as a $99 \%$ decrease in the signal, and is $\sim 300 \mu \mathrm{m}$. Parameter values used are from the predicted regime; $g_{s b}=5, g_{b s}=5.75 \mathrm{nS}, c_{s b}=$ 0.21 . 
way we estimated that there would be $\sim 22,000$ PYR cells that contributed to the LFP signal. We note that this would be an upper bound, as we assumed correlated activity across PYR cells and homogeneous extracellular electrical properties.

\section{Discussion}

To a large extent, understanding brain function and coding requires that we are able to understand how oscillatory LFP signals are generated (Einevoll et al., 2013; Friston et al., 2015; Hyafil et al., 2015). Cross-frequency coupling analyses of LFP signals has led to ideas underlying learning and memory functioning (Canolty and Knight, 2010), and it is always important to do careful analyses (Scheffer-Teixeira and Tort, 2016). Further, given that particular inhibitory cell populations and abnormalities in $\theta$ rhythms are associated with disease states (Colgin, 2016), we need to consider how different cell types and pathways contribute to LFP recordings. Ultimately, the challenge is to bring together LFP studies from experimental, modeling and analysis perspectives. In this work, we make steps toward this challenge by gaining insight into the contribution of OLM cells to intrinsic $\theta$ rhythms as exhibited by an in vitro whole hippocampus preparation.

\section{$\theta$ rhythms and summary of results}

The existence of $\theta$ rhythms $(3-12 \mathrm{~Hz})$ in the hippocampus has long been known, and these prevalent rhythms are associated with memory processing and spatial navigation (Colgin, 2013, 2016). These rhythms are present when the animal is actively exploring and during REM sleep. Further, they can be separated into higher or lower frequencies that are atropine resistant or atropine sensitive, respectively (Buzsáki, 2002; Colgin, 2013, 2016). Recent work has shown that low $\theta$ rhythms were elicited in rats with fearful stimuli and high $\theta$ with social stimuli (Tendler and Wagner, 2015). In vitro models of $\theta$ rhythms in the hippocampus have been developed (Gillies et al., 2002) as well as network mathematical models (Neymotin et al., 2011; Hummos and Nair, 2017), but it is challenging to bring about a mechanistic understanding of $\theta$ rhythms in vivo due to their various forms and pharmacological sensitivities combined with the interactions that occur between the hippocampus and other brain structures.

While it is clear that different interneuron subtypes are involved in $\theta$ rhythms (Colgin, 2013, 2016), it is difficult to untangle the cellular contributions to resulting $\theta$ rhythms exhibited in extracellular LFP recordings. That the required circuitry for $\theta$ rhythms has been shown to be present in local circuits of the hippocampus (Colgin and Moser, 2009) is both useful and helpful as it becomes more likely that biophysical LFP models can be linked to a cellular-based circuit understanding of $\theta$ rhythms. We took advantage of the in vitro whole hippocampus preparation that spontaneously expressed intrinsic $\theta$ rhythms (Goutagny et al., 2009), and previous inhibitory network models developed for this experimental context (Ferguson et al., 2015), to build biophysical LFP models.

The LFP is generated on the basis of transmembrane currents. This means that the LFP is a weighted sum of inward and outward currents. How the LFP changes as a function of location is not trivial. In our work here, when the LFP is governed by synaptic inputs the LFP peaks are narrower since the synaptic inputs are synchronized because of the coherent inhibitory spike rasters. On the other hand, LFP signals governed by return currents would produce LFP peaks that are less narrow as the signal slows down as it travels down the dendrites producing a time lag. This all thus translates to synaptic input location dependencies. Thus, while we can visualize and appreciate the synergistic balances between excitation and inhibition from different cell populations, we note that these combinations are not easily seen as summated balances. Signal decompositions and intuitions from many simulations are required. We leveraged our LFP models to make direct comparison with experimental LFP characteristics. This allowed us to constrain coupling parameters which in turn led us to understand the cellular contribution of interneuron subtypes, specifically OLM cells, to intrinsic $\theta$ LFP rhythms.

We showed how the extracellular $\theta$ field recorded along the cellular axis of a PYR cell was affected by the magnitude of the inhibitory synaptic currents inserted along its dendritic arbor. Fluctuations in the magnitude of the total inhibitory input occurred due to alterations in synaptic strength balances of the inhibitory networks. Our models exhibited network states in which interactions between OLM cells and BiCs could invert the polarity of the recorded signal and produce extracellular potentials of high or low magnitude. We also distinguished regimes where these cellular interactions preserved the frequency of the signal versus those that led to lags or abolishment of the extracellular LFP rhythm. When we applied experimental characteristics of $\theta$ frequencies and polarities to our biophysical LFP models, a clear selection emerged and thus we were able to constrain parameter values regarding connectivities. Specifically, we found that the connection probability from OLM cells to BiCs needed to be 0.21 and that synaptic conductances from OLM cells to BiCs had to be larger than $3.5 \mathrm{nS}$, and we called this the predicted regime.

Unexpectedly, we found that this predicted regime also exhibited a robust power output. That is, so long as parameter values were within the predicted regime, the power did not change (Fig. 7A), and in this regime we saw that BiCs were mostly silenced, BC/ACCs were significantly active while OLM cell activity decreased from high to low values as $g_{b s}$ increased (Fig. 2C). By decomposing the signal, we revealed that OLM cell inputs minimally contributed to the LFP power unlike the other cell populations (BiCs and BC/AACs or PV cells). The power of the OLM cell LFP component on its own, although low, showed some variation in the predicted regime [coefficient of variation $(\mathrm{CV})<1]$. On the other hand, the power of the PV cell LFP component was a couple of orders of magnitude higher and showed more variation $(\mathrm{CV}>1)$ in the predicted regime. This indicates that OLM cells contributed to LFP power robustness without contributing to average power whereas PV cells contributed to average power but their effect was more sensitive to perturbations in OLM-BiC interactions. Therefore, their contribution was 
variable. It is however interesting to note that the PV LFP component average power was larger than the average power of the predicted regime with all cells being present. Thus, our results indicated that adding OLM cells in the network can overall cause a small decrease in LFP average power as compared to when only PV cells were present and of course induce robustness. It was also interesting to observe that in almost half of the cases the OLM cell LFP component was arrhythmic or nonoscillatory despite the fact that OLM cells were driven by $\theta$-paced EPSCs. That is, OLM cell inputs alone in most cases were not able to generate a $\theta$ LFP signal as recorded in the extracellular space of the PYR cell although OLM cell populations themselves were firing at $\theta$ frequency. Further LFP signal analysis decomposition showed that removing only basal excitation disrupted the robustness of the predicted regime. This suggests that a synergy of OLM cell inputs and basal excitatory inputs as coactivation of distal inhibition and proximal excitation is important to produce robustness in the predicted regime. Overall, an essential aspect in comparing model and experiment LFPs to predict model parameters and decipher cellular contributions was to match sources and sinks at different layers. Thus, having recordings from multiple layers is important.

\section{Morphologic details, synaptic locations, and related studies}

As the main contribution to the LFP is thought to stem from synaptic input to neurons and the subthreshold dendritic processing, various studies have investigated how morphologic characteristics and intrinsic resonances shape the features of the LFP signal. In most cases input synapses are activated according to Poissonian statistics (Lindén et al., 2010; Łęski et al., 2013; Ness et al., 2016). However, in our study here, the origin population consisted of point neuron cell representations that had been constrained based on experimental patch clamp recordings from the whole hippocampus preparation. We used a scheme which is a combination of point neuron origin populations and a multi-compartment PYR cell model which served as a processor of synaptic inputs and produced the LFP. This scheme is conceptually very similar to the hybrid scheme proposed in Hagen et al. (2016).

One factor modulating the amplitude of LFPs was related to the somatodendritic location of synaptic inputs on the PYR cell tree. Different populations of GABAergic interneurons target different dendritic domains and the domain-specific targeting of various interneurons supports the hypothesis of domain-specific synaptic integration in CA1 PYR cells (Spruston, 2008). In CA1 PYR cells, distal and middle apical dendrites comprise two distinct dendritic domains with separate branching connected by a thick apical dendrite. This cytoarchitectonic separation of the cluster of distal dendrites relative to middle and proximal dendrites was shown to critically reduce the effect of distal EPSCs to somatic excitability (Srinivas et al., 2017). The presence of a single apical dendrite with many obliques in stratum radiatum caused a large shunting of EPSCs traveling from the tuft dendrites to the soma.
Thus, we can appreciate our observation that OLM cells, which target distal dendrites, minimally affected LFP power in SP considering the limited ability of distal inhibition to reach more proximal and somatic regions of the CA1 PYR where maximum power was recorded. This is not just due to the distal location of these inputs but more due to the cytoarchitectonic separation of the cluster of distal dendrites relative to middle and proximal dendrites. This separation prohibited inhibitory inputs in distal regions from effectively propagating to somatic and proximal regions of CA1 PYR cells and thus being reflected in the extracellular space.

We can further consider our results in light of another theoretical modeling study by Gidon and Segev (2012), which showed that inhibitory inputs can affect excitatory inputs locally and/or globally, depending on the relative locations of the excitatory and inhibitory synapses. In particular, this can help us understand the loss of robust power in the predicted regime after removal of OLM cells. The predicted regime consists of different connectivities that generated different spiking patterns that gave rise to fluctuations in inhibitory input in different synaptic locations. First, inhibitory input hyperpolarized the membrane potential, which resulted in shunting of the adjacent dendritic compartments. Activation of excitatory synapses within the shunted compartments will thus generate smaller depolarization, compared with non-shunted dendrites ("local" effect). Second, the local shunting would suppress excitatory input in a nonlinear fashion at locations that were not directly affected by the shunting ("global" effect). Thus, when inhibitory inputs were activated simultaneously with excitatory inputs, the average (i.e., across trials) evoked membrane potential within shunted dendritic compartments should be smaller compared with compartments that had no inhibitory input. At the same time, excitatory effects throughout the entire dendritic tree would be reduced in a nonlinear fashion, and which can be quantified as the change (with vs without inhibitory input) of the trial-to-trial variability of the membrane potential. In our case the activation of excitatory inputs occurred in regions not close by the OLM cell inhibitory inputs, thus the overall power did not increase but the robustness was affected. In Gidon and Segev (2012), the authors examined the spread of shunt level implications using a CA1 reconstructed neuron model receiving inhibition at three distinct dendritic subdomains: the basal, the apical, and the oblique dendrites as innervated by inhibitory synapses. They found that the shunt level spread effectively hundreds of micrometers centripetally to the contact sites themselves spanning from the distal dendrites to the somatic area. This observation thus showed that the somatic area was indeed influenced by shunting inhibition which means that excitatory input nonlinearities in our model will be reduced in the presence of global inhibition in the somatic area leading to a decrease in variability and thus robustness in the membrane potential. Of course, the LFP is a measurement of transmembrane currents and not membrane potential. However, the reduction of excitatory input mediated non-linearities will 
also reduce the variability in the distribution of return currents and thus the variability in the LFP.

\section{Limitations and future considerations}

Our present study was limited in terms of not considering more inhibitory cell types (Bezaire et al., 2016) and by considering ongoing intrinsic $\theta$ rhythms since $\theta$ frequency inputs were used (Fig. 1). However, our inhibitory network models were constrained by the experimental context and our less complex model representations enabled us to explore many thousands of simulations and directly compare our biophysical LFPs with experimental LFP features. This aspect was key in allowing us to constrain parameter value sets and to gain insights.

$\theta$ rhythms are foremost generated due to subthreshold activity and dendritic processing of synaptic inputs. Here, we used a passive PYR cell model as the spiking component has been shown to mainly contribute to the LFP at frequencies higher than $90 \mathrm{~Hz}$ (Schomburg et al., 2012), while the active voltage-gated channels that were eliminated here were shown to influence LFP characteristics more prominently in frequencies above the $\theta$ range (Reimann et al., 2013). Thus, although the presence of voltage-gated channels will influence the exact distribution of return currents, we thought that it was a reasonable simplification to not include them in this study. Indeed, in an additional set of simulation (data not shown), we observed that the presence of hyperpolarization-activated cyclic nucleotide-gated (HCN) channels on the PYR cell did not influence the sink-source LFP profile and frequency examined here, although it did affect the wave form characteristics.

Another limitation is the usage of a single PYR cell to predict network dynamics. However, we note here that since the LFP is a linear summation of the transmembrane currents in the extracellular space (Equation 1), incorporating more PYR cells could result in a linear additive effect in the extracellular space. This would lead to the same LFP profiles as in the case of a single cell only significantly magnified provided that the cells have a similar morphology, physically arborizing in ways that facilitate superposition rather than cancellations of fields, and receive similar presynaptic inputs. Indeed, there is a homogeneous cytoarchitecture disposition of the PYR cells across the CA1 layer (Andersen et al., 2006) and is one of the factors responsible for the extracellular sinks and sources recorded in CA1. Also, PYR cells receive similar presynaptic inputs from the presynaptic populations which project on the same layers across cells. For this reason, we do think that the conclusions derived from the single cell LFP output will remain on the network level to some extent. Of course, important variabilities across PYR cells also exist and considering them in future studies will be important (Soltesz and Losonczy, 2018). Therefore, careful network modeling will be required to assess the network-generated LFP output.

Extracellular studies suggest that the main current generators of field $\theta$ waves are the coherent dendritic and somatic membrane potential fluctuations of the orderly aligned PYR cells (Winson, 1978; Buzsàki and Eidelberg,
1983; Brankačk et al., 1993). Thus, distal and local ascending pathways onto PYR cells can in principle contribute to extracellular LFP deflections. To understand $\theta$ rhythms one needs to consider the populations projecting onto the PYR cells in CA1. During in vivo behaviors, medial septum and entorhinal cortical inputs onto CA1 PYR cells are prominent modulators of the amplitude, phase and wave form features of $\theta$ rhythms in conjunction with local inhibitory and excitatory cells. However, spatiotemporal coincidence of inputs makes separation difficult and thus it is challenging to determine cellular contributions to LFP recordings. As there is significant spatiotemporal overlap on PYR cell dendrites across ascending pathways it would be hard to disentangle the cellular composition of these pathways and assess the cellular contribution to $\theta$ LFP characteristics. As shown in previous studies (Makarova et al., 2011) blind separation techniques such as Independent Component Analysis produce poor results when trying to disentangle combinations of rhythmic synaptic sources with extensive spatiotemporal overlap. By focusing on intrinsic $\theta$ rhythms in the in vitro whole hippocampus preparation here, we reduced the spatiotemporal overlap of different pathways and unraveled the cellular composition of the different pathways projecting to the PYR cell. We were thus able to decipher the contribution of OLM cells to intrinsic $\theta$ rhythms. This work could potentially be used as a basis to understand OLM cell contributions during in vivo $\theta$ LFP recordings.

Moving forward we aim to take advantage of the insights gained here to build hypothesis-driven $\theta$ generating networks. In this way, we hope to be able to determine the contribution of different cell types and pathways to LFP recordings that are so heavily used and interpreted in neuroscience today.

\section{References}

Amilhon B, Huh CYL, Manseau F, Ducharme G, Nichol H, Adamantidis A, Williams S (2015) Parvalbumin interneurons of hippocampus tune population activity at theta frequency. Neuron 86:12771289. CrossRef

Andersen P, Morris R, Amaral D, Bliss T, O'Keefe J (2006) The hippocampus book, Ed 1. Oxford: Oxford University Press.

Baude A, Bleasdale C, Dalezios Y, Somogyi P, Klausberger T (2007) Immunoreactivity for the GABAA receptor alpha1 subunit, somatostatin and connexin36 distinguishes axoaxonic, basket, and bistratified interneurons of the rat hippocampus. Cereb Cortex 17: 2094-2107. CrossRef

Bezaire MJ, Soltesz I (2013) Quantitative assessment of CA1 local circuits: knowledge base for interneuron-pyramidal cell connectivity. Hippocampus 23:751-785.

Bezaire MJ, Raikov I, Burk K, Vyas D, Soltesz I (2016) Interneuronal mechanisms of hippocampal theta oscillation in a full-scale model of the rodent CA1 circuit. Elife 5:e18566. CrossRef

Brankačk J, Stewart M, E Fox S (1993) Current source density analysis of the hippocampal theta rhythm: associated sustained potentials and candidate synaptic generators. Brain Res 615:310327. CrossRef

Buzsáki G (2002) Theta oscillations in the hippocampus. Neuron 33:325-340. Medline

Buzsáki G (2006) Rhythms of the brain, Ed 1. Oxford: Oxford University Press.

Buzsàki G, Eidelberg E (1983) Phase relations of hippocampal projection cells and interneurons to theta activity in the anesthetized rat. Brain Res 266:334-339. CrossRef 
Buzsáki G, Draguhn A (2004) Neuronal oscillations in cortical networks. Science 304:1926-1929.

Buzsáki G, Anastassiou CA, Koch C (2012) The origin of extracellular fields and currents - EEG, ECoG, LFP and spikes. Nat Rev Neurosci 13:407-420. CrossRef

Canolty RT, Knight RT (2010) The functional role of cross-frequency coupling. Trends Cogn Sci 14:506-515. CrossRef

Carmichael JE, Gmaz JM, van der Meer MAA (2017) Gamma oscillations in the rat ventral striatum originate in the piriform cortex. $J$ Neurosci 37:7962-7974. CrossRef

Carnevale NT, Hines ML (2006) The NEURON book. Cambridge: Cambridge University Press.

Colgin LL (2013) Mechanisms and functions of theta rhythms. Annu Rev Neurosci 36:295-312. CrossRef

Colgin LL (2016) Rhythms of the hippocampal network. Nat Rev Neurosci 17:239-249. CrossRef

Colgin LL, Moser El (2009) Hippocampal theta rhythms follow the beat of their own drum. Nat Neurosci 12:1483-1484. CrossRef

Einevoll GT, Kayser C, Logothetis NK, Panzeri S (2013) Modelling and analysis of local field potentials for studying the function of cortical circuits. Nat Rev Neurosci 14:770-785. CrossRef

Ferguson KA, Huh CYL, Amilhon B, Williams S, Skinner FK (2013) Experimentally constrained CA1 fast-firing parvalbumin-positive interneuron network models exhibit sharp transitions into coherent high frequency rhythms. Front Comput Neurosci 7:144. CrossRef

Ferguson KA, Huh CYL, Amilhon B, Manseau F, Williams S, Skinner FK (2015) Network models provide insights into how orienslacunosum-moleculare and bistratified cell interactions influence the power of local hippocampal CA1 theta oscillations. Front Syst Neurosci 9:110. CrossRef

Ferguson KA, Chatzikalymniou AP, Skinner FK (2017) Combining theory, model, and experiment to explain how intrinsic theta rhythms are generated in an in vitro whole hippocampus preparation without oscillatory inputs. eNeuro 4. CrossRef

Friston KJ, Bastos AM, Pinotsis D, Litvak V (2015) LFP and oscillations-what do they tell us? Curr Opin Neurobiol 31:1-6. CrossRef

Gidon A, Segev I (2012) Principles governing the operation of synaptic inhibition in dendrites. Neuron 75:330-341. CrossRef

Gillies MJ, Traub RD, LeBeau FEN, Davies CH, Gloveli T, Buhl EH, Whittington MA (2002) A model of atropine-resistant theta oscillations in rat hippocampal area CA1. J Physiol 543:779-793. CrossRef

Goutagny R, Jackson J, Williams S (2009) Self-generated theta oscillations in the hippocampus. Nat Neurosci 12:1491-1493. CrossRef

Hagen E, Dahmen D, Stavrinou ML, Lindén H, Tetzlaff T, van Albada SJ, Grün S, Diesmann M, Einevoll GT (2016) Hybrid scheme for modeling local field potentials from point-neuron networks. Cereb Cortex 26:4461-4496. CrossRef

Hattori R, Kuchibhotla KV, Froemke RC, Komiyama T (2017) Functions and dysfunctions of neocortical inhibitory neuron subtypes. Nat Neurosci 20:1199-1208. CrossRef

Herreras O (2016) Local field potentials: myths and misunderstandings. Front Neural Circuits 10:101. CrossRef

Huh CYL, Amilhon B, Ferguson KA, Manseau F, Torres-Platas SG, Peach JP, Scodras S, Mechawar N, Skinner FK, Williams S (2016) Excitatory inputs determine phase-locking strength and spiketiming of CA1 stratum oriens/alveus parvalbumin and somatostatin interneurons during intrinsically generated hippocampal theta rhythm. J Neurosci 36:6605-6622. CrossRef

Hummos A, Nair SS (2017) An integrative model of the intrinsic hippocampal theta rhythm. PLoS One 12:e0182648. CrossRef

Hyafil A, Giraud AL, Fontolan L, Gutkin B (2015) Neural crossfrequency coupling: connecting architectures, mechanisms, and functions. Trends Neurosci 38:725-740. CrossRef

Izhikevich EM (2003) Simple model of spiking neurons. IEEE Trans Neural Netw 14:1569-1572. CrossRef

Kepecs A, Fishell G (2014) Interneuron cell types are fit to function. Nature 505:318-326.
Klausberger T, Somogyi P (2008) Neuronal diversity and temporal dynamics: the unity of hippocampal circuit operations. Science 321:53-57. CrossRef

Leão RN, Mikulovic S, Leão KE, Munguba $H$, Gezelius $H$, Enjin $A$, Patra K, Eriksson A, Loew LM, Tort AB, Kullander K (2012) OLM interneurons differentially modulate $C A 3$ and entorhinal inputs to hippocampal CA1 neurons. Nat Neurosci 15:1524-1530. CrossRef

Łęski S, Lindén H, Tetzlaff T, Pettersen KH, Einevoll GT (2013) Frequency dependence of signal power and spatial reach of the local field potential. PLoS Comput Biol 9:e1003137. CrossRef

Lindén H, Pettersen KH, Einevoll GT (2010) Intrinsic dendritic filtering gives low-pass power field potentials. J Comput Neurosci 29:423444. CrossRef

Lindén H, Hagen E, Lęski S, Norheim ES, Pettersen KH, Einevoll GT (2014) LFPy: a tool for biophysical simulation of extracellular potentials generated by detailed model neurons. Front Neuroinform 7:41. CrossRef

Loken C, Gruner D, Groer L, Peltier R, Bunn N, Craig M, Henriques T, Dempsey J, Yu CH, Chen J, Dursi LJ, Chong J, Northrup S, Pinto J, Knecht N, Van Zon R (2010) SciNet: lessons learned from building a power-efficient top-20 system and data centre. J Phys Conf Ser 256:012026. CrossRef

López-Aguado L, Ibarz JM, Herreras O (2001) Activity-dependent changes of tissue resistivity in the CA1 region in vivo are layerspecific: modulation of evoked potentials. Neuroscience 108:249262. CrossRef

Maccaferri G (2005) Stratum oriens horizontal interneurone diversity and hippocampal network dynamics. J Physiol 562:73-80. CrossRef

Maccaferri G, David J, Roberts B, Szucs P, Cottingham CA, Somogyi P (2000) Cell surface domain specific postsynaptic currents evoked by identified GABAergic neurones in rat hippocampus in vitro. J Physiol 524:91-116. CrossRef

Makarova J, Ibarz JM, Makarov VA, Benito N, Herreras O (2011) Parallel readout of pathway-specific inputs to laminated brain structures. Front Syst Neurosci 5:77. CrossRef

Migliore M, Migliore R (2012) Know your current I h: interaction with a shunting current explains the puzzling effects of its pharmacological or pathological modulations. PLoS One 7:e36867. CrossRef

Ness TV, Remme MWH, Einevoll GT (2016) Active subthreshold dendritic conductances shape the local field potential. J Physiol 3809-3825. CrossRef

Neymotin SA, Lazarewicz MT, Sherif M, Contreras D, Finkel LH, Lytton WW (2011) Ketamine disrupts theta modulation of gamma in a computer model of hippocampus. J Neurosci 31:1173311743. CrossRef

Nicholson C, Freeman JA (1975) Theory of current source-density analysis and determination of conductivity tensor for anuran cerebellum. J Neurophysiol 38:356-368. CrossRef

Nunez PL, Srinivasan R (2006) Electric fields of the brain: the neurophysics of EEG. Oxford: Oxford University Press.

Pettersen KH, Lindén H, Dale AM, Einevoll GT (2012) Extracellular spikes and CSD. In: Handbook of neural activity measurement (Brette R, Destexhe A, eds), pp 92-135. Cambridge: Cambridge University Press.

Potworowski J, Jakuczun W, Lẹski S, Wójcik DK (2012) Kernel current source density method. Neural Comput 24:541-575. CrossRef

Reimann MW, Anastassiou CA, Perin R, Hill SL, Markram H, Koch C (2013) A biophysically detailed model of neocortical local field potentials predicts the critical role of active membrane currents. Neuron 79:375-390. CrossRef

Scheffer-Teixeira R, Tort AB (2016) On cross-frequency phasephase coupling between theta and gamma oscillations in the hippocampus. Elife 5:e20515. CrossRef

Schomburg EW, Anastassiou CA, Buzsáki G, Koch C (2012) The spiking component of oscillatory extracellular potentials in the rat hippocampus. J Neurosci 32:11798-11811. CrossRef 
Siegle JH, Wilson MA (2014) Enhancement of encoding and retrieval functions through theta phase-specific manipulation of hippocampus. Elife 3:e03061. CrossRef

Soltesz I, Losonczy A (2018) CA1 pyramidal cell diversity enabling parallel information processing in the hippocampus. Nat Neurosci 21:484-493. CrossRef

Spruston N (2008) Pyramidal neurons: dendritic structure and synaptic integration. Nat Rev Neurosci 9:206-221.

Srinivas KV, Buss EW, Sun Q, Santoro B, Takahashi H, Nicholson DA, Siegelbaum SA (2017) The dendrites of CA2 and CA1 pyramidal neurons differentially regulate information flow in the corticohippocampal circuit. J Neurosci 37:3276-3293. CrossRef
Takács VT, Klausberger T, Somogyi P, Freund TF, Gulyás Al (2012) Extrinsic and local glutamatergic inputs of the rat hippocampal CA1 area differentially innervate pyramidal cells and interneurons. Hippocampus 22:1379-1391. CrossRef

Tendler A, Wagner S (2015) Different types of theta rhythmicity are induced by social and fearful stimuli in a network associated with social memory. Elife 4:e03614. CrossRef

Wilson MA, Varela C, Remondes M (2015) Phase organization of network computations. Curr Opin Neurobiol 31:250-253. CrossRef

Winson J (1978) Loss of hippocampal theta rhythm results in spatial memory deficit in the rat. Science 201:160-163. CrossRef 